\title{
Use of the Bethe equation for inner-shell ionization by electron impact
}

\author{
Cedric J. Powell, ${ }^{1}$ Xavier Llovet, ${ }^{2}$ and Francesc Salvat ${ }^{3}$ \\ ${ }^{1}$ Materials Measurement Science Division, National Institute of Standards and Technology, Gaithersburg, \\ Maryland 20899-8370, USA \\ ${ }^{2}$ Centres Científics i Tecnològics, Universitat de Barcelona, Lluís Solé i Sabarís 1-3, 08028 Barcelona, Spain \\ ${ }^{3}$ Facultat de Física (ECM and ICC), Universitat de Barcelona, Diagonal 645, 08028 Barcelona, Spain
}

(Received 23 February 2016; accepted 25 April 2016; published online 13 May 2016)

\begin{abstract}
We analyzed calculated cross sections for K-, L-, and M-shell ionization by electron impact to determine the energy ranges over which these cross sections are consistent with the Bethe equation for inner-shell ionization. Our analysis was performed with K-shell ionization cross sections for 26 elements, with L-shell ionization cross sections for seven elements, $\mathrm{L}_{3}$-subshell ionization cross sections for Xe, and M-shell ionization cross sections for three elements. The validity (or otherwise) of the Bethe equation could be checked with Fano plots based on a linearized form of the Bethe equation. Our Fano plots, which display theoretical cross sections and available measured cross sections, reveal two linear regions as predicted by de Heer and Inokuti [in Electron Impact Ionization, edited by T. D. Märk and G. H. Dunn, (Springer-Verlag, Vienna, 1985), Chap. 7, pp. 232-276]. For each region, we made linear fits and determined values of the two element-specific Bethe parameters. We found systematic variations of these parameters with atomic number for both the low- and the high-energy linear regions of the Fano plots. We also determined the energy ranges over which the Bethe equation can be used. Published by AIP Publishing.
\end{abstract}

[http://dx.doi.org/10.1063/1.4948700]

\section{INTRODUCTION}

Cross sections for ionization of inner-shell electrons in neutral atoms by electron impact are needed in many branches of physics, including atomic physics, plasma physics, radiation physics, materials analysis by electronprobe microanalysis (EPMA), surface analysis by Augerelectron spectroscopy (AES), and thin-film analysis by electron energy-loss spectroscopy. These cross sections are often used in Monte Carlo simulations to predict, for example, radiation transport in matter and the generation of X-ray and Auger-electron signal intensities in EPMA and AES.

In 1930 , Bethe ${ }^{1}$ developed a non-relativistic asymptotic expression for the cross section, per atom, for ionization of shell $i$ in the form

$$
\sigma_{i}=\frac{\pi e^{4}}{E} \frac{Z_{i} b_{i}}{E_{i}} \ln \left[\frac{c_{i} E}{E_{i}}\right],
$$

where $E=m v^{2} / 2$ is the kinetic energy of the incident electrons, $v$ is the electron velocity, $E_{i}$ is the binding energy of electrons in shell $i, Z_{i}$ is the number of electrons in that shell, and $e$ and $m$ are the electronic charge and mass, respectively. The parameters $b_{i}$ and $c_{i}$ in Eq. (1) are given by

$$
b_{i}=E_{i} M_{i}^{2} / Z_{i}
$$

and

$$
\ln \left(\frac{c_{i} m c^{2}}{2 E_{i}}\right)=\frac{C_{i}}{M_{i}^{2}},
$$

where $c$ is the velocity of light. The term $M_{i}^{2}$ in Eqs. (2) and (3) is the square of the total dipole-matrix element for ionizing collisions while the term $C_{i}$ in Eq. (3) is given by an integral of the generalized oscillator strength for inner-shell ionization. ${ }^{2}$ The parameter $b_{i}$ was estimated by Bethe (using hydrogenic wave functions) to be between 0.2 and 0.6 for inner shells and, for a given shell, to be a function of atomic number, $Z$. The parameter $c_{i}$ was estimated by Bethe to be about 4. Equation (1) was derived with use of the first Born approximation and is expected to be valid when $E \gg E_{i}$ and when the average energy transfer in the ionizing collision is much less than $E .^{2}$ A relativistic version of Eq. (1), given as Eq. (4) below, was published by Fano. ${ }^{3}$

Despite the wide use of Eq. (1) and its relativistic counterpart for estimating cross sections for inner-shell ionization, there is limited knowledge of the Bethe parameters $b_{i}$ and $c_{i}$ and of the energy ranges over which these equations can be expected to be valid. Powell ${ }^{4-6}$ reported values of the Bethe parameters from fits to measured cross sections for inner-shell ionization, but the resulting parameter values were of necessity limited to the elements and energy ranges for which measurements were available.

We report a new analysis to determine the ranges of incident energy over which the Bethe equation is valid and the corresponding values of the Bethe parameters $b_{i}$ and $c_{i}$. We make use of cross sections for K-, L-, and M-shell ionization that were calculated by Bote et al. ${ }^{7,8}$ using a composite algorithm that combines the distorted-wave and plane-wave Born approximations. Llovet et $a .^{9}{ }^{9}$ recently reviewed these calculated cross sections and the available measured cross sections. They identified elements for which there were at least three (for K shells) or two (for L and M subshells) mutually consistent sets of cross-section measurements and for which the cross sections varied with energy as expected by theory; these selections were referred to as superior values. Llovet et al. 
found that the overall average root-mean-square deviation between the calculated cross sections and the selected measured values was $10.9 \%$ and the overall average deviation was $-2.5 \%$. This degree of agreement was considered to be very satisfactory given the difficulties of making absolute crosssection measurements. 9

A simple but valuable method of analyzing sets of crosssections for inner-shell ionization (or indeed any other inelastic-scattering cross sections ${ }^{10}$ ) is the Fano plot. ${ }^{2-6,10}$ As suggested by the non-relativistic Bethe equation [Eq. (1)], a Fano plot is made by plotting $\sigma_{i} E E_{i}$ (e.g., from a set of measured or calculated cross sections over a particular energy range) versus $\ln \left(E / E_{i}\right)$; as we will see, a similar type of plot can be made based on the relativistic Bethe equation. If such a plot is judged to be linear, we can conclude that the data set is consistent with the Bethe equation and derive values of the Bethe parameters. ${ }^{4-6}$ However, de Heer and Inokuti ${ }^{11}$ have pointed out that Fano plots should display two linear regions if the energy range for the data set is sufficiently large. At relatively low energies, one linear region is found typically beginning at several times the threshold energy for inner-shell ionization, $E_{i}{ }^{4}$ Another linear region is expected at higher energies with a smaller slope that occurs in what is termed the asymptotic Bethe region.

The cross sections for $\mathrm{K}-, \mathrm{L}-$, and M-shell ionization that were calculated by Bote et al. ${ }^{7,8}$ extend from the threshold energy for ionization to $100 \mathrm{GeV}$. The large energy range for these cross sections is thus well suited for a more
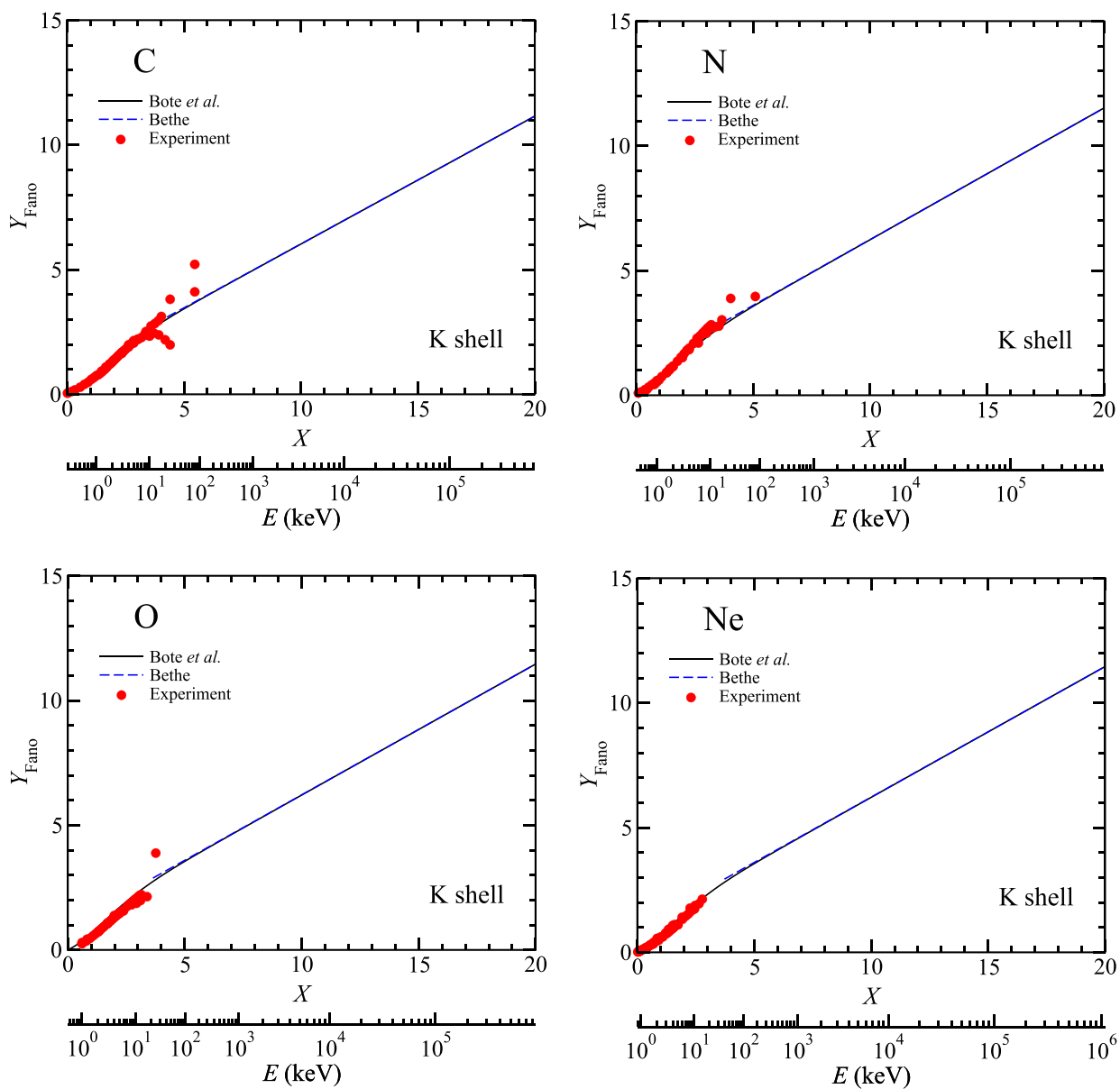

FIG. 1. Fano plots for $\mathrm{C}, \mathrm{N}, \mathrm{O}, \mathrm{Ne}, \mathrm{Al}$, and $\mathrm{Si}$ (solid lines) based on $\mathrm{K}$-shell ionization cross sections calculated by Bote et al..$^{7,8}$ in which $Y_{\text {Fano }}$ from Eq. (7) is plotted against $X$ from Eq. (6). The abscissa also shows the electron kinetic energy, $E$. The dashed lines show linear fits to the $Y_{\text {Fano }}$ values from the calculated cross sections with Eq. (8) in the asymptotic highenergy region of the Fano plots. The dashed lines have been extrapolated to a lower energy at which the deviation from the solid lines is 5\%. The solid circles show values of $Y_{\text {Fano }}$ calculated from the preferred measured $\mathrm{K}$-shell ionization cross sections of Llovet et al. (Tables 2 and 7 of Ref. 9).
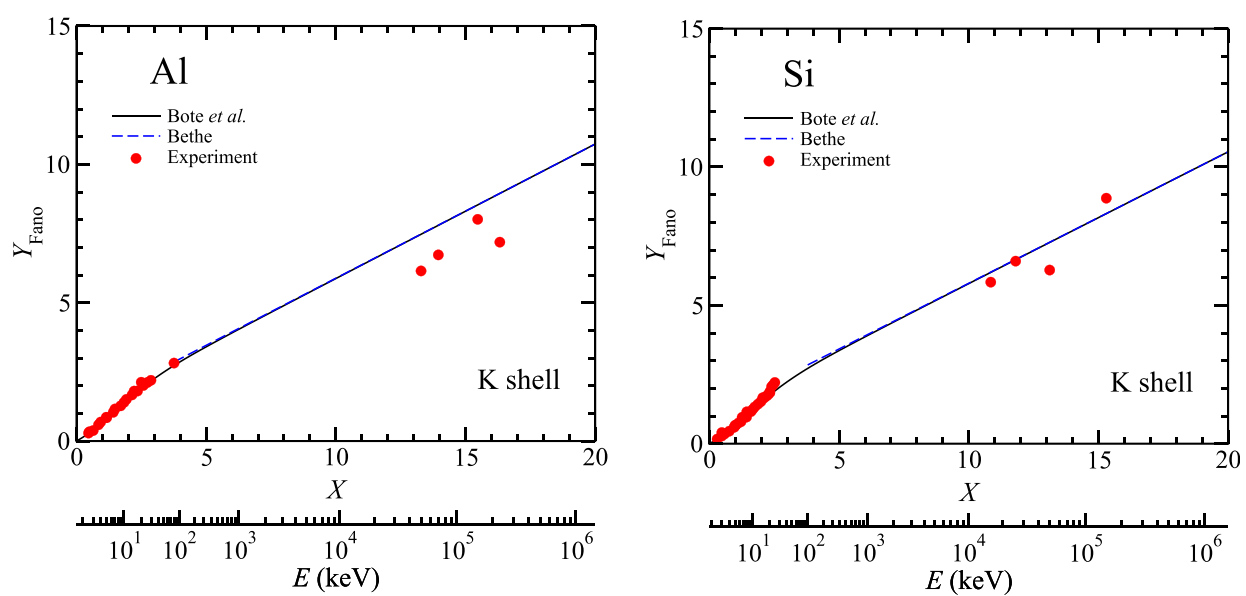
extensive analysis of the Bethe equation based on Fano plots. Llovet et al. ${ }^{9}$ identified 26 elements (C, N, O, Ne, Al, Si, Ar, $\mathrm{Ca}, \mathrm{Ti}, \mathrm{Cr}, \mathrm{Mn}, \mathrm{Fe}, \mathrm{Ni}, \mathrm{Cu}, \mathrm{Zn}, \mathrm{Ga}, \mathrm{Ge}, \mathrm{Se}, \mathrm{Y}, \mathrm{Pd}, \mathrm{Ag}, \mathrm{Sn}$, $\mathrm{Sb}, \mathrm{Au}, \mathrm{Pb}$, and $\mathrm{Bi}$ ) with measured $\mathrm{K}$-shell ionization cross sections that satisfied their selection criteria. They similarly identified seven elements ( $\mathrm{Ag}, \mathrm{Sn}, \mathrm{Sm}, \mathrm{Ta}, \mathrm{Pb}, \mathrm{Bi}$, and $\mathrm{U}$ ) with satisfactory measurements of total L-shell ionization cross sections and one element (Xe) with satisfactory measurements of $\mathrm{L}_{3}$-subshell ionization cross sections. Finally, Llovet et al. identified three elements ( $\mathrm{Au}, \mathrm{Pb}$, and $\mathrm{Bi})$ that had satisfactory measurements of total M-shell ionization cross sections. We present Fano plots for each of these elements based on the calculated ionization cross sections. These plots clearly show the existence of two distinct linear regions, and we derive values of the Bethe parameters for each linear region. We then show systematic variations of the derived Bethe parameters with atomic number for the two linear regions and systematic differences in the Bethe parameters for K-, L-, and M-shell ionization.

\section{THE FANO PLOT}

The relativistic form of the Bethe equation for innershell ionization is ${ }^{2,3}$

$$
\sigma_{i}=\frac{2 \pi e^{4}}{m v^{2}} \frac{Z_{i} b_{i}}{E_{i}}\left\{\left[\ln \left(\frac{\beta^{2}}{1-\beta^{2}}\right)-\beta^{2}\right]+\ln \left(\frac{c_{i} m c^{2}}{2 E_{i}}\right)\right\},
$$
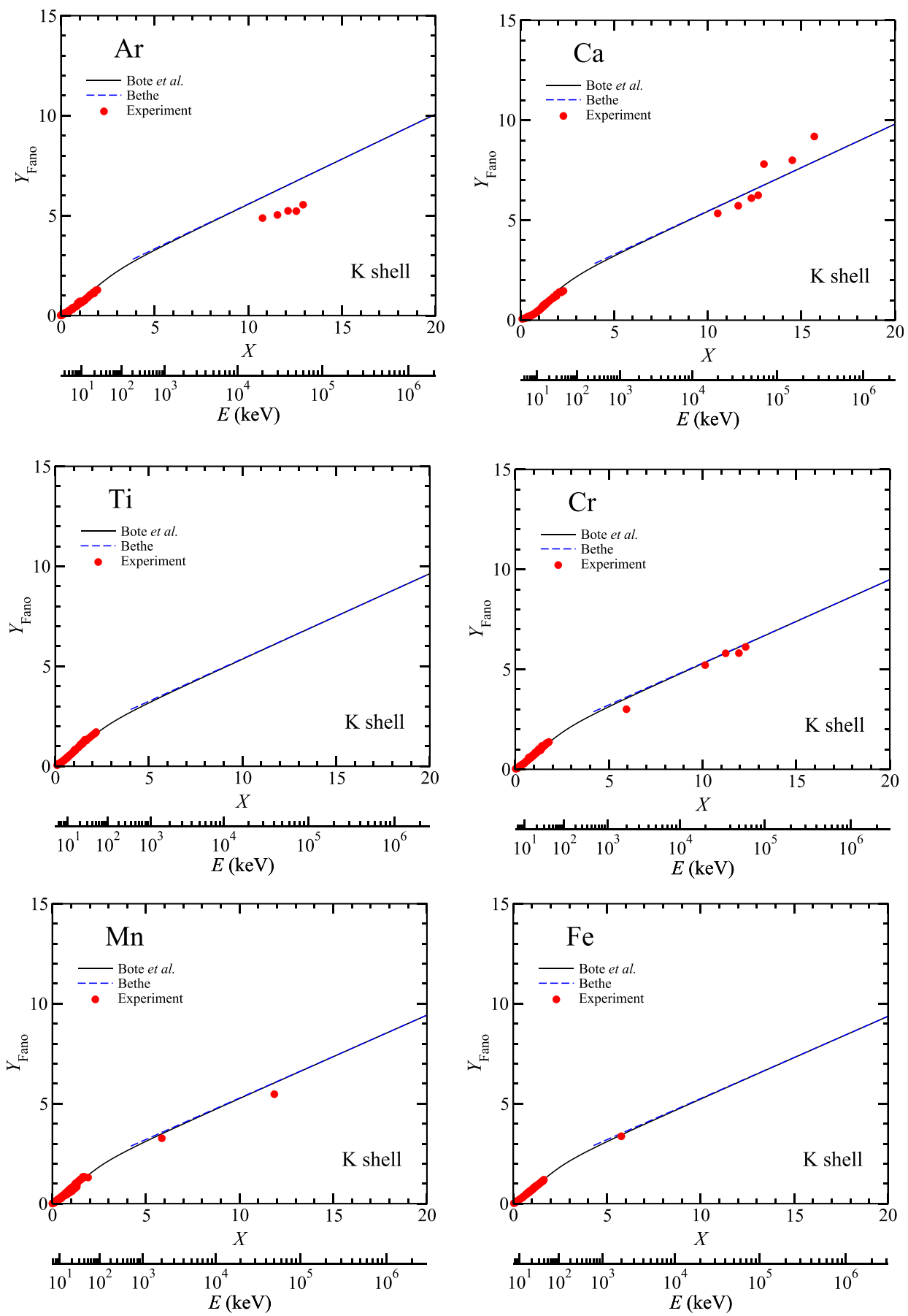

FIG. 2. Fano plots for $\mathrm{Ar}, \mathrm{Ca}, \mathrm{Ti}, \mathrm{Cr}$, $\mathrm{Mn}$, and Fe; see caption to Fig. 1. 
where $\beta$ is the ratio of the electron velocity to the velocity of light, $c$. It is convenient to rewrite Eq. (4) as

$$
\sigma_{i}=\frac{2 \pi e^{4}}{m v^{2}} \frac{Z_{i} b_{i}}{E_{i}}\left(X+\ln c_{i}\right)=\frac{2 \pi e^{4}}{m v^{2}} M_{i}^{2}\left(X+\ln c_{i}\right),
$$

where

$$
X=\left[\ln \left(\frac{\beta^{2}}{1-\beta^{2}}\right)-\beta^{2}\right]+\ln \left(\frac{m c^{2}}{2 E_{i}}\right) .
$$

A Fano plot is prepared by plotting

$$
Y_{\text {Fano }}=\frac{\sigma_{i} m v^{2} E_{i}}{2 \pi e^{4} Z_{i}}
$$

versus $X$ as suggested by Eq. (5). For linear regions of the Fano plot,

$$
Y_{\text {Fano }}=b_{i}\left(X+\ln c_{i}\right) .
$$

The Bethe parameter $b_{i}$ is the slope of the linear region of the plot, and the parameter $c_{i}$ is determined by the ordinate at $X=0$, where $Y_{\text {Fano }}=b_{i} \ln c_{i}$. In the nonrelativistic limit, $X \approx \ln \left(E / E_{i}\right)=\ln U$ and $m c^{2} \beta^{2} \approx 2 E$ where $U=E / E_{i}$ is the overvoltage and $E$ is the electron kinetic energy. Equation (7) then becomes

$$
Y_{\mathrm{Fano}}=\frac{\sigma_{i} E_{i}^{2} U}{\pi e^{4} Z_{i}}=\frac{\sigma_{i} E E_{i}}{\pi e^{4} Z_{i}} .
$$
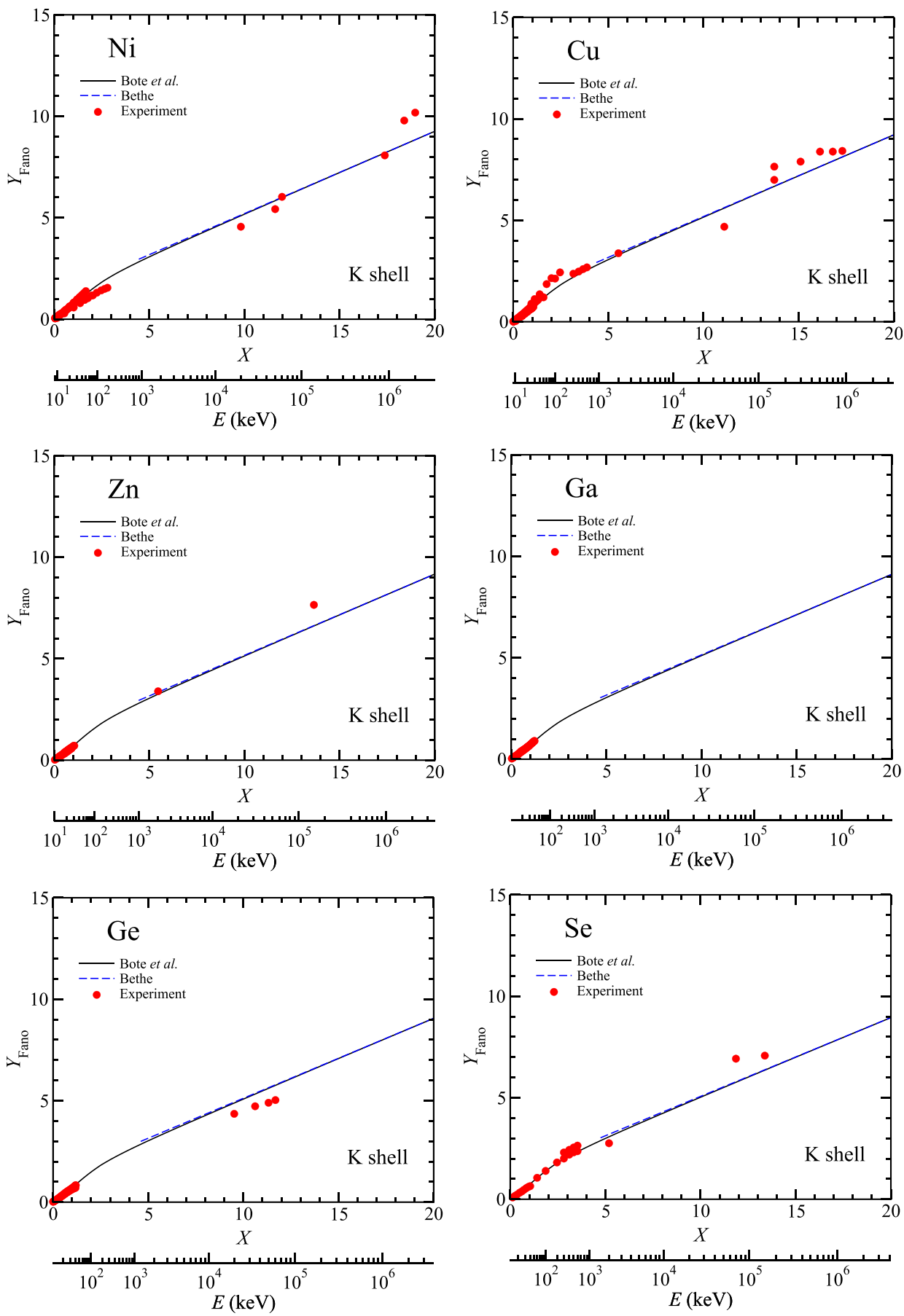

FIG. 3. Fano plots for $\mathrm{Ni}, \mathrm{Cu}, \mathrm{Zn}, \mathrm{Ga}$, $\mathrm{Ge}$, and Se; see caption to Fig. 1. 
For ionization of $\mathrm{L}$ and $\mathrm{M}$ shells, we need to determine appropriate values of $E_{i}$ and $Z_{i}$ depending on whether particular or all subshells contribute to the relevant ionization process. For ionization of all $\mathrm{L}$ subshells, for example, we have

$$
M_{\mathrm{L}}^{2}=\sum_{j=1}^{3} M_{\mathrm{L} j}^{2}
$$

and

$$
\ln c_{\mathrm{L}}=\frac{1}{M_{\mathrm{L}}^{2}} \sum_{j=1}^{3} M_{\mathrm{L} j}^{2} \ln c_{\mathrm{L} j}
$$

where $M_{\mathrm{L} j}^{2}$ is the total dipole-matrix element squared for ionization of L-subshell $j$ and $c_{\mathrm{L} j}$ is the corresponding value of the parameter $c_{i}$. The total number of electrons in the $\mathrm{L}$ shell is

$$
Z_{\mathrm{L}}=\sum_{j=1}^{3} Z_{\mathrm{L} j}=8
$$

and the average $\mathrm{L}$-shell binding energy, $\overline{E_{\mathrm{L}}}$, is

$$
\overline{E_{\mathrm{L}}}=\frac{1}{Z_{\mathrm{L}}} \sum_{j=1}^{3} Z_{\mathrm{L} j} E_{\mathrm{L} j}
$$
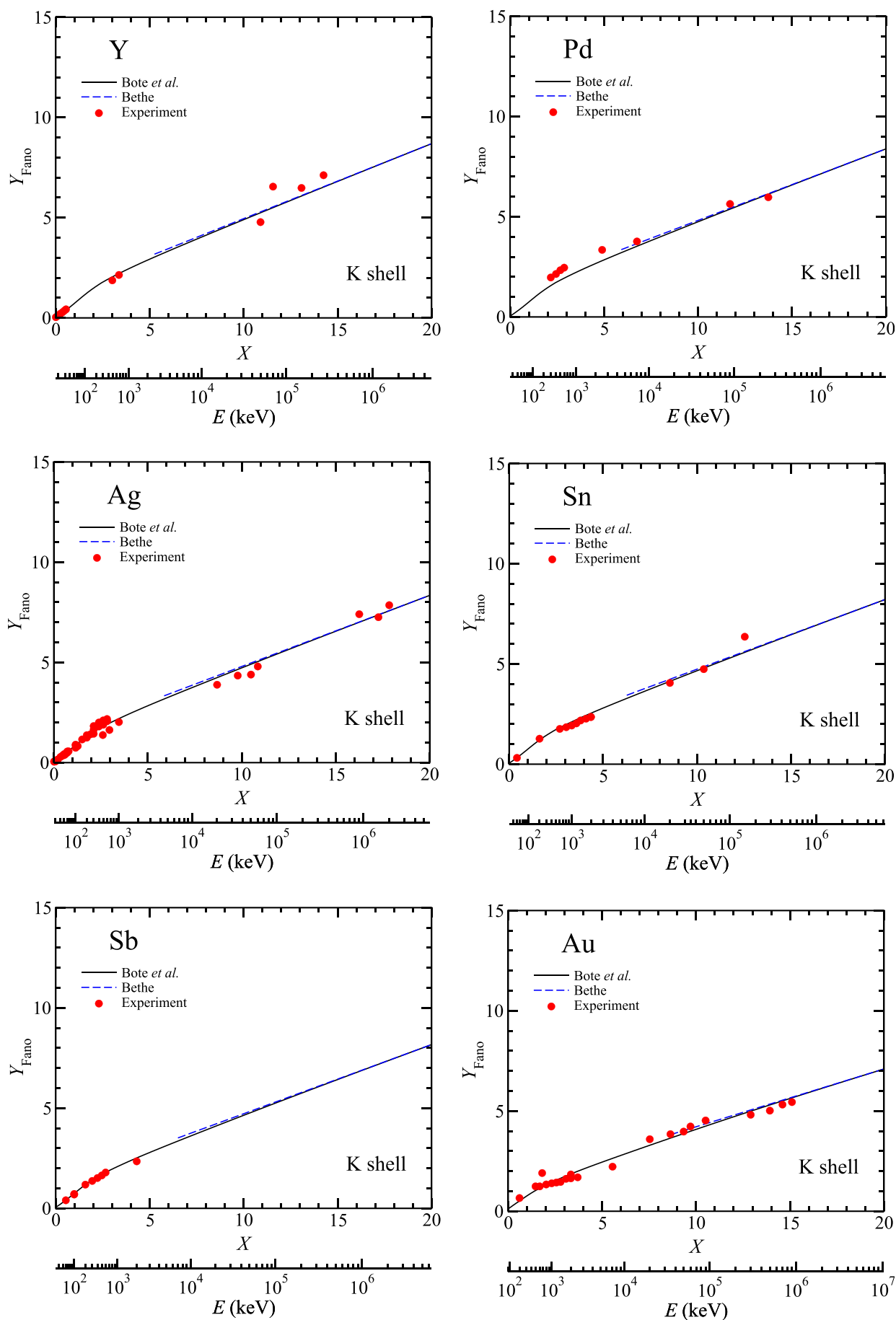

FIG. 4. Fano plots for Y, Pd, Ag, Sn, $\mathrm{Sb}$, and $\mathrm{Au}$; see caption to Fig. 1. 

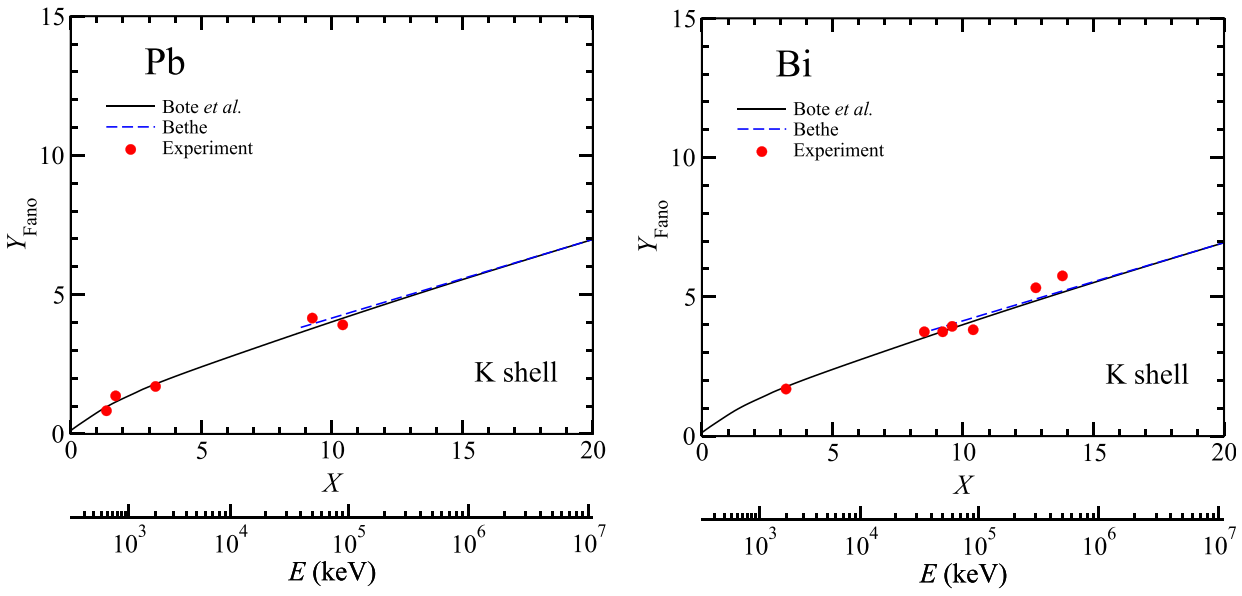

FIG. 5. Fano plots for $\mathrm{Pb}$ and $\mathrm{Bi}$; see caption to Fig. 1. where $Z_{\mathrm{L} j}$ is the number of electrons in L-subshell $j$ and $E_{\mathrm{L} j}$ is the binding energy for these electrons. Similar equations can be written for ionization of all M subshells.

\section{RESULTS}

\section{A. K-shell ionization cross sections}

Figures 1-5 show Fano plots in which $Y_{\text {Fano }}$ from Eq. (7) is plotted (solid lines) against $X$ from Eq. (6) for $\mathrm{C}, \mathrm{N}, \mathrm{O}$, $\mathrm{Ne}, \mathrm{Al}, \mathrm{Si}, \mathrm{Ar}, \mathrm{Ca}, \mathrm{Ti}, \mathrm{Cr}, \mathrm{Mn}, \mathrm{Fe}, \mathrm{Ni}, \mathrm{Cu}, \mathrm{Zn}, \mathrm{Ga}, \mathrm{Ge}, \mathrm{Se}, \mathrm{Y}$, $\mathrm{Pd}, \mathrm{Ag}, \mathrm{Sn}, \mathrm{Sb}, \mathrm{Au}, \mathrm{Pb}$, and $\mathrm{Bi}$. In these plots, we have used the K-shell ionization cross sections, $\sigma_{\mathrm{K}}$, calculated by Bote et $a l^{7,8}$ and the $\mathrm{K}$-shell binding energies tabulated by Williams. $^{12}$ The abscissa also shows the corresponding electron kinetic energy, $E$. The Fano plots extend from the threshold for K-shell ionization $(X=0)$ to $X=20$ where the maximum energy ranges from $600 \mathrm{MeV}$ to $10 \mathrm{GeV}$. The solid circles in Figs. 1-5 show values of $Y_{\text {Fano }}$ calculated from Eq. (7) with the preferred measurements of K-shell ionization cross sections of Llovet et al. (Tables 2 and 7 of Ref. 9) versus $X$ from Eq. (6).

The Fano plots in Figs. 1-5 display two linear regions, as expected from the discussion of de Heer and Inokuti. ${ }^{11}$ We will now determine values of the Bethe parameters for each linear region. The dashed lines in Figs. 1-5 show linear fits with Eq. (8) to the $Y_{\text {Fano }}$ values from the calculated cross sections in the asymptotic high-energy regions of the Fano plots. The dashed lines have been extrapolated to a minimum energy, $E_{\min }$, at which the deviation from the solid lines becomes $5 \%$. Table I shows values of the Bethe parameters $b_{\mathrm{K}}$ and $c_{\mathrm{K}}$ from the fits for each element, the values of $E_{\mathrm{min}}$, and the corresponding overvoltage, $U_{\min }$. We note that no uncertainties are given for the values of $b_{\mathrm{K}}$ and $c_{\mathrm{K}}$ since values of $b_{\mathrm{K}}$ were determined from the asymptotic slopes of the Fano plots and then values of $c_{\mathrm{K}}$ from the corresponding ordinate values at $X=0$ where $Y=b_{\mathrm{K}} \ln c_{\mathrm{K}}$. We see that the values of $b_{\mathrm{K}}$ in Table I are about 0.52 for $\mathrm{C}, \mathrm{N}, \mathrm{O}$, and $\mathrm{Ne}$, and then gradually decrease with increasing $Z$ to 0.281 for $\mathrm{Bi}$. The values of $c_{\mathrm{K}}$ in Table I, however, increase from 5.85 for $\mathrm{C}$ to 116 for $\mathrm{Bi}$.

The solid lines in Figs. 6-10 show expanded views of the low-energy regions of the Fano plots in Figs. 1-5, from $X=0$ to $X=4$. The dashed lines in Figs. 6-10 indicate linear fits to the $Y_{\text {Fano values from the calculated cross sections }}$ with Eq. (8) over energy regions, $E_{\min }$ to $E_{\max }$, where the deviations with respect to the solid lines are less than $5 \%$. Table II shows values of the derived Bethe parameters $b_{\mathrm{K}}$ and $c_{\mathrm{K}}$ and their one-standard-deviation uncertainties from the fits for each element, the values of $E_{\min }$ and $E_{\max }$, and the corresponding overvoltage values, $U_{\min }$ and $U_{\max } . \mathrm{We}$ see that $b_{\mathrm{K}}$ decreases from 0.806 for $\mathrm{C}$ and about 0.84 for $\mathrm{N}$, $\mathrm{O}$, and $\mathrm{Ne}$ to about 0.58 for $\mathrm{Pb}$ and $\mathrm{Bi}$. These $b_{\mathrm{K}}$ values are about $50 \%$ larger than those in Table I for the low- $Z$

TABLE I. Values of the Bethe parameters, $b_{\mathrm{K}}$ and $c_{\mathrm{K}}$, derived from the linear fits with Eq. (8) in the high-energy asymptotic regions of the Fano plots with K-shell ionization cross sections in Figs. 1-5. We also show the minimum kinetic energy, $E_{\min }$, at which the deviation of the fitted lines in the Fano plots of Figs. 1-5 becomes $5 \%$ and the corresponding value of the overvoltage, $U_{\min }$.

\begin{tabular}{|c|c|c|c|c|c|}
\hline Element & $Z$ & $b_{\mathrm{K}}$ & $c_{\mathrm{K}}$ & $E_{\min }(\mathrm{keV})$ & $U_{\min }$ \\
\hline $\mathrm{C}$ & 6 & 0.512 & 5.85 & 11.7 & 41.0 \\
\hline $\mathrm{N}$ & 7 & 0.527 & 6.25 & 16.1 & 39.3 \\
\hline $\mathrm{O}$ & 8 & 0.524 & 6.37 & 21.9 & 40.3 \\
\hline $\mathrm{Ne}$ & 10 & 0.524 & 6.58 & 36.3 & 41.7 \\
\hline $\mathrm{Al}$ & 13 & 0.485 & 8.41 & 73.6 & 47.2 \\
\hline $\mathrm{Si}$ & 14 & 0.475 & 9.03 & 91.2 & 49.6 \\
\hline $\mathrm{Ar}$ & 18 & 0.449 & 11.5 & 199.5 & 62.2 \\
\hline $\mathrm{Ca}$ & 20 & 0.435 & 12.8 & 275.4 & 68.2 \\
\hline $\mathrm{Ti}$ & 22 & 0.426 & 14.0 & 374.4 & 75.4 \\
\hline $\mathrm{Cr}$ & 24 & 0.418 & 15.1 & 501.2 & 83.7 \\
\hline $\mathrm{Mn}$ & 25 & 0.414 & 15.7 & 566.7 & 86.7 \\
\hline $\mathrm{Fe}$ & 26 & 0.411 & 16.2 & 640.7 & 90.1 \\
\hline $\mathrm{Ni}$ & 28 & 0.405 & 17.3 & 806.6 & 96.8 \\
\hline $\mathrm{Cu}$ & 29 & 0.403 & 17.8 & 898.1 & 100.0 \\
\hline $\mathrm{Zn}$ & 30 & 0.400 & 18.4 & 1000 & 103.5 \\
\hline $\mathrm{Ga}$ & 31 & 0.397 & 19.1 & 1113 & 107.4 \\
\hline $\mathrm{Ge}$ & 32 & 0.394 & 19.9 & 1240 & 111.7 \\
\hline $\mathrm{Se}$ & 34 & 0.388 & 21.3 & 1468 & 116.0 \\
\hline $\mathrm{Y}$ & 39 & 0.374 & 25.7 & 2291 & 134.5 \\
\hline $\mathrm{Pd}$ & 46 & 0.357 & 32.9 & 4105 & 168.6 \\
\hline $\mathrm{Ag}$ & 47 & 0.355 & 34.0 & 4365 & 171.1 \\
\hline $\mathrm{Sn}$ & 50 & 0.347 & 38.0 & 5580 & 191.1 \\
\hline $\mathrm{Sb}$ & 51 & 0.345 & 39.5 & 6026 & 197.6 \\
\hline $\mathrm{Au}$ & 79 & 0.288 & 101 & 31623 & 391.7 \\
\hline $\mathrm{Pb}$ & 82 & 0.283 & 113 & 38019 & 432.0 \\
\hline $\mathrm{Bi}$ & 83 & 0.281 & 116 & 39204 & 433.1 \\
\hline
\end{tabular}



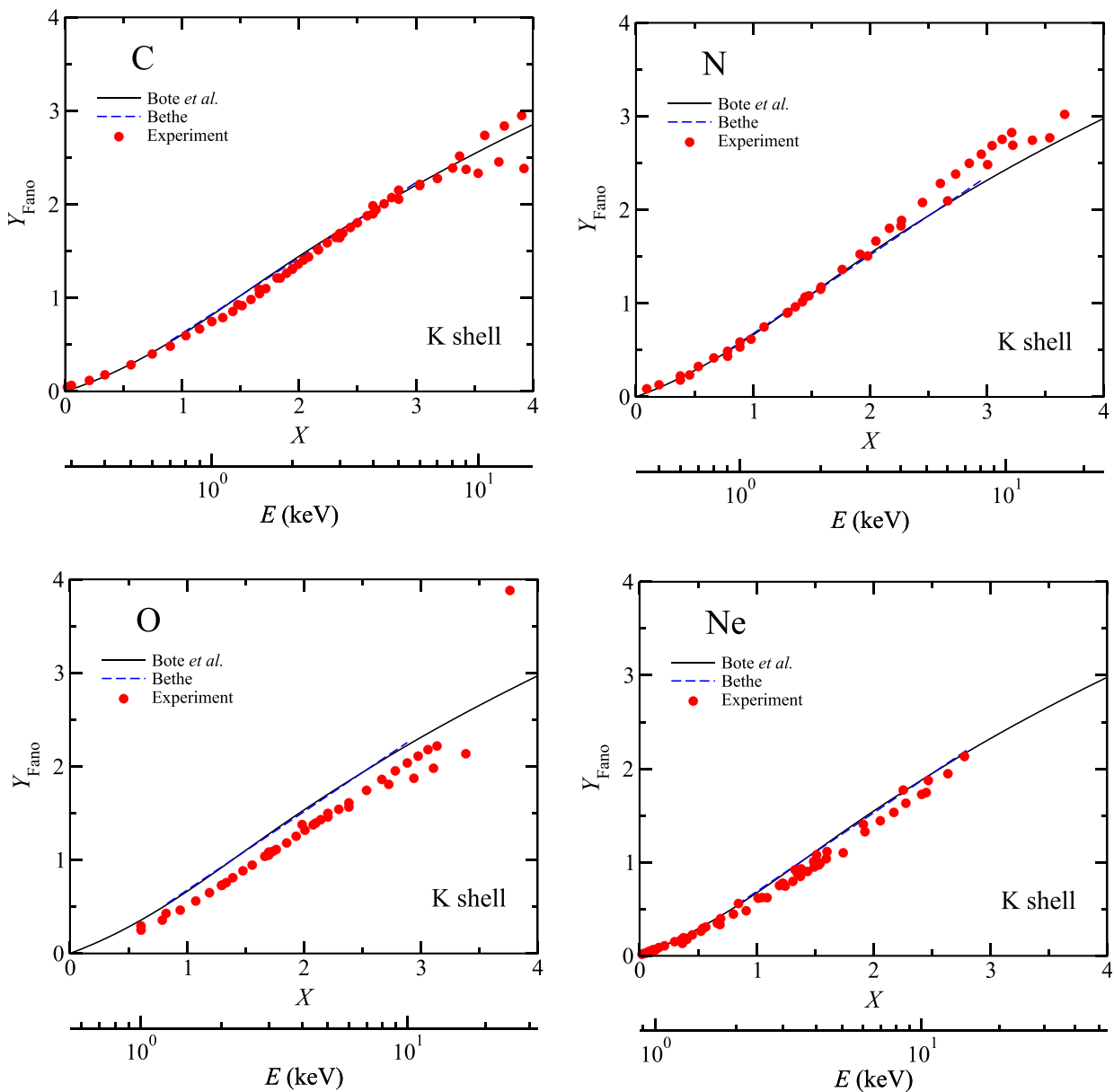

FIG. 6. Expanded view of the Fano plots for $\mathrm{C}, \mathrm{N}, \mathrm{O}, \mathrm{Ne}, \mathrm{Al}$, and $\mathrm{Si}$ in Fig. 1 (solid lines) from $X=0$ to $X=4$. The abscissa also shows the electron kinetic energy, $E$. The dashed lines show linear fits to the $Y_{\text {Fano }}$ values from the calculated cross sections with Eq. (8) over the energy range, $E_{\min }$ to $E_{\max }$, where the deviations from the solid lines are less than $5 \%$. The solid circles show values of $Y_{\text {Fano }}$ calculated from the preferred measured $\mathrm{K}$-shell ionization cross sections of Llovet et al. (Tables 2 and 7 of Ref. 9).
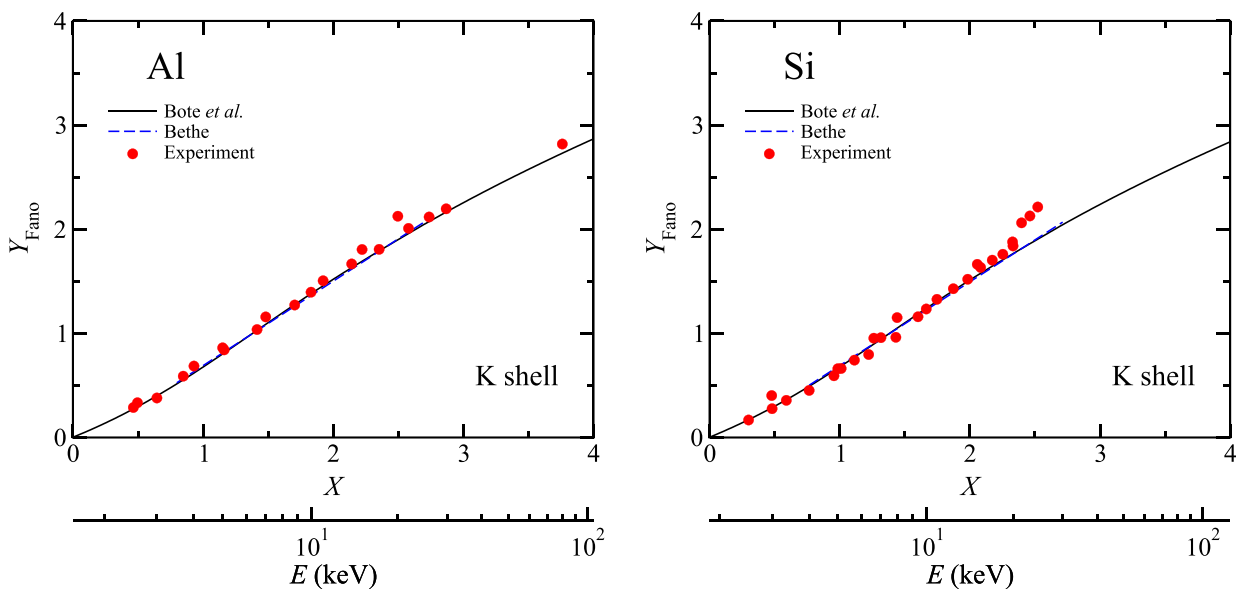

elements and about $100 \%$ larger than those in Table I for the high- $Z$ elements. In contrast to the relatively large increases of $c_{\mathrm{K}}$ in Table I with increasing $Z$ for the high-energy regions of the Fano plots (an increase by a factor of about 20), the values of $c_{\mathrm{K}}$ in Table II increase from $0.796 \pm 0.002$ for $\mathrm{C}$ to $1.333 \pm 0.007$ for $\mathrm{Bi}$, an increase of less than a factor of 2 . We note that the fractional uncertainties for $c_{\mathrm{K}}$ in Table II are larger than those for $b_{\mathrm{K}}$ because the uncertainties in $c_{\mathrm{K}}$ are determined from the uncertainties of both $b_{\mathrm{K}}$ and $b_{\mathrm{K}} \ln c_{\mathrm{K}}$ in each fit with Eq. (8).

We see from Table II that the linear regions in Figs. 6-10 range from $U_{\min } \approx 1.7$ to $U_{\max } \approx 8$ for the high- $Z$ elements while the linear regions for the low- $Z$ elements range from $U_{\min } \approx 2.2$ to $U_{\max } \approx 20$. The linear regions for the elements
C through Ni occur, as a group, from $U_{\min }=2.3$ to $U_{\max }$ $=15.6$. This overvoltage range is comparable with that of the 1976 Powell $^{4}$ analysis (4-24) although the lower limit of the overvoltage range found here (2.3) is about a factor of 2 smaller than in the sets of data analyzed by Powell.

Values of $U_{\min }$ for the high-energy linear regions in Table I range from about 40 for the low- $Z$ elements to about 400 for the high- $Z$ elements. Values of $U_{\max }$ for the lowenergy linear regions in Table II range from about 20 for the low- $Z$ elements to about 8 for the high- $Z$ elements. The Fano plots thus change their slopes (between the two linear regions) over a narrow range of $X$ for the low- $Z$ elements in Fig. 1 while the slope change is much more gradual for the high- $Z$ elements in Figs. 4 and 5. 

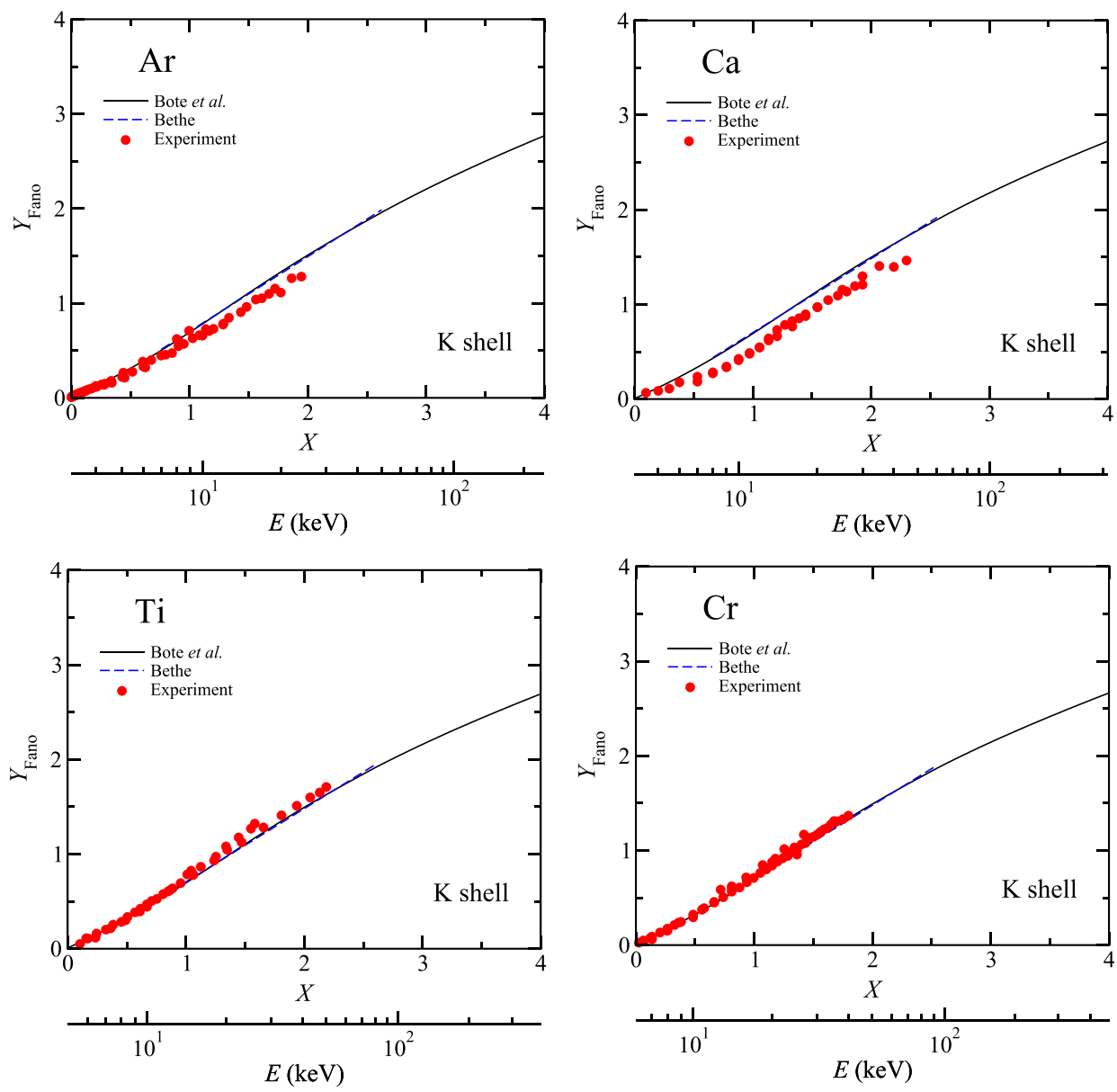

FIG. 7. Expanded view of the Fano plots for $\mathrm{Ar}, \mathrm{Ca}, \mathrm{Ti}, \mathrm{Cr}, \mathrm{Mn}$, and $\mathrm{Fe}$ in Fig. 2 from $X=0$ to $X=4$; see caption to Fig. 6.

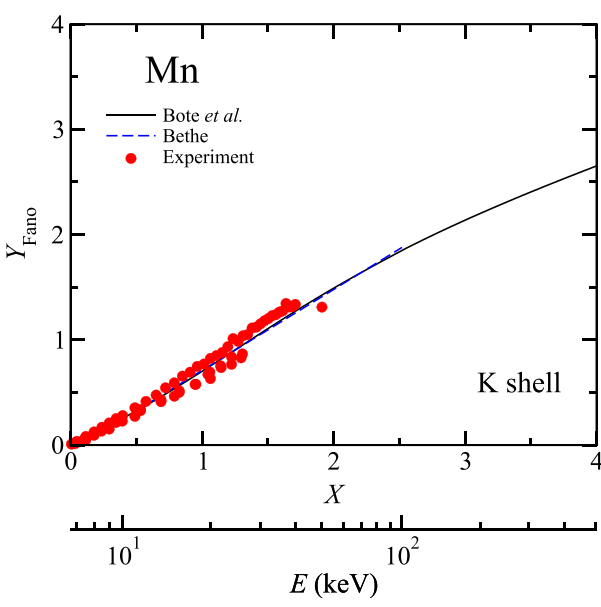

\section{B. L-shell ionization cross sections}

Figures 11 and 12 show Fano plots based on total cross sections for L-shell ionization, $\sigma_{\mathrm{L}}$, in $\mathrm{Ag}, \mathrm{Sn}, \mathrm{Sm}, \mathrm{Ta}, \mathrm{Pb}, \mathrm{Bi}$, and U. As for Figs. 1-10, we have plotted $Y_{\text {Fano }}$ from Eq. (7) versus $X$ from Eq. (6). The solid lines show $Y_{\text {Fano }}$ with the calculated cross sections of Bote et al. ${ }^{7,8}$ and the solid circles show $Y_{\text {Fano }}$ with the preferred measured cross sections of Llovet et al. (Tables 3 and 9 of Ref. 9). Values of $Y_{\text {Fano }}$ from Eq. (7) were calculated with the average L-shell binding energies determined from the L-subshell binding energies of Williams ${ }^{12}$ for each element that were weighted by the corresponding subshell occupancy numbers, as indicated by Eq. (11b). The abscissas in Figs. 11 and 12 also show the electron

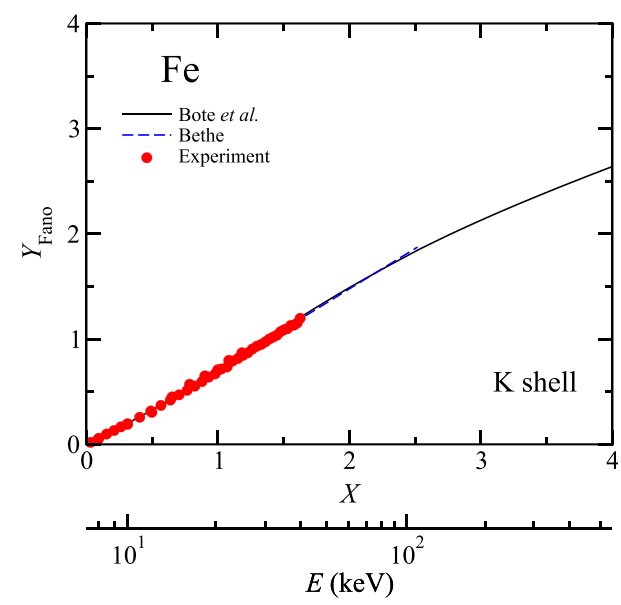

kinetic energy. As before, the Fano plots extend from the ionization threshold $(X=0)$ to $X=20$ where the maximum energy is between $2 \mathrm{GeV}$ and $5 \mathrm{GeV}$.

The Fano plots in Figs. 11 and 12 display two linear regions like those in Figs. 1-5 for K-shell ionization. We have again made linear fits to the $Y_{\text {Fano }}$ values from the calculated cross sections with Eq. (8) in the asymptotic highenergy linear regions of each Fano plot. These fits, indicated by the dashed lines, have been extrapolated, as before, to a minimum energy, $E_{\min }$, at which the deviations from the solid lines become 5\%. Table III shows the Bethe parameters, $b_{\mathrm{L}}$ and $c_{\mathrm{L}}$, from each fit, the values of $E_{\min }$, and the corresponding values of $U_{\min }$. We see that the values of $b_{\mathrm{L}}$ in Table III decrease from about 0.42 for $\mathrm{Ag}$ to about 0.31 for 

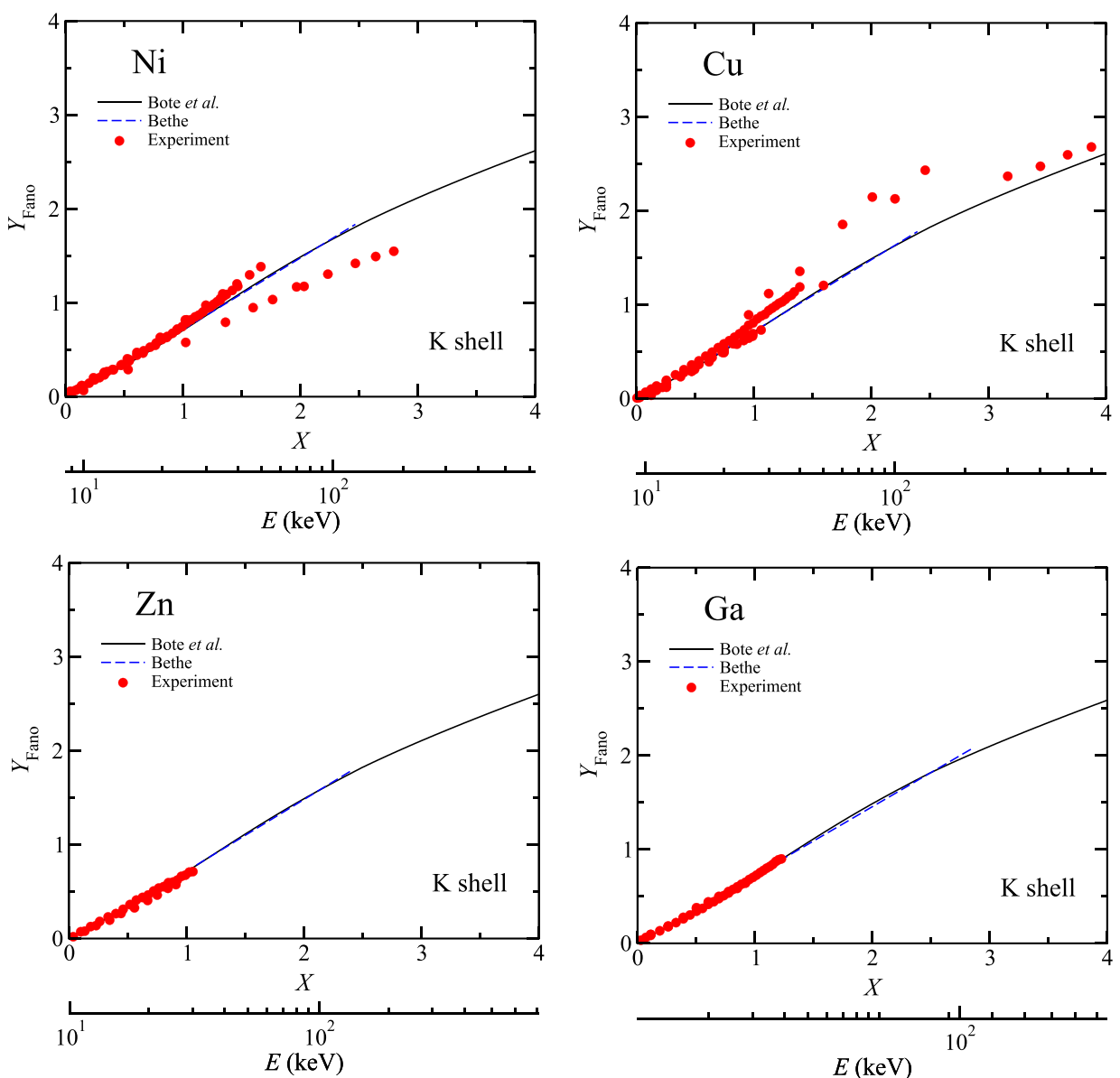

$E(\mathrm{keV})$
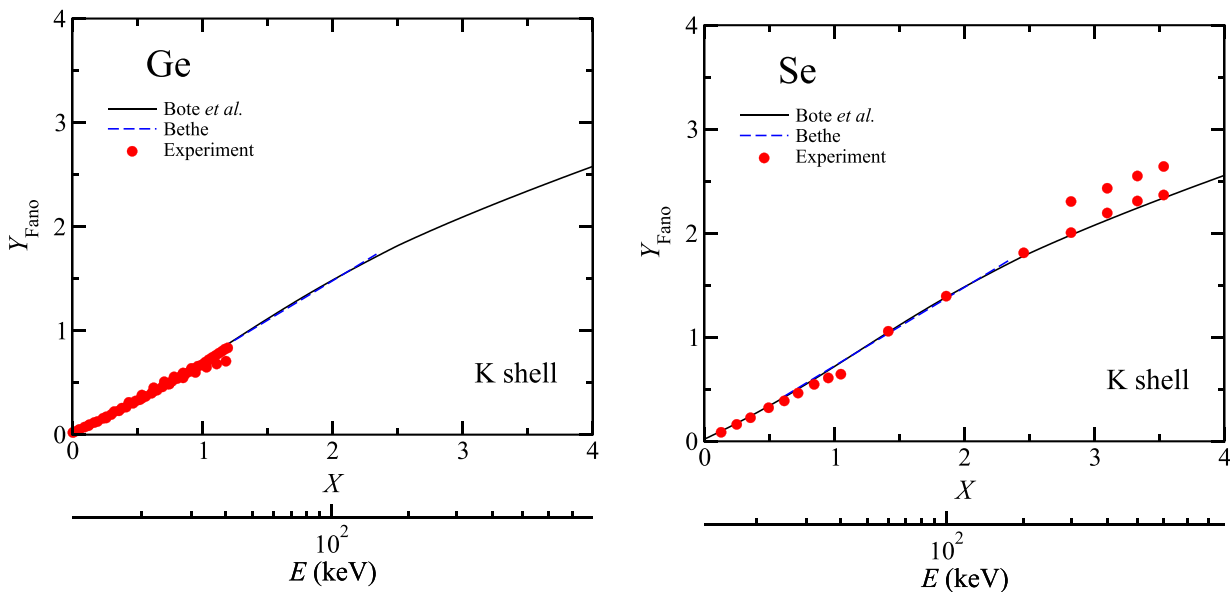

FIG. 8. Expanded view of the Fano plots for $\mathrm{Ni}, \mathrm{Cu}, \mathrm{Zn}, \mathrm{Ga}, \mathrm{Ge}$, and $\mathrm{Se}$ in Fig. 3 from $X=0$ to $X=4$; see caption to Fig. 6 .
$\mathrm{U}$ while the values of $c_{\mathrm{L}}$ increase from about 15 for $\mathrm{Ag}$ to about 70 for U. The $b_{\mathrm{L}}$ values in Table III are between $11 \%$ and $17 \%$ larger than the values of $b_{\mathrm{K}}$ in Table I that decrease from about 0.36 for $\mathrm{Ag}$ to about 0.28 for $\mathrm{Bi}$. However, the $c_{\mathrm{L}}$ values in Table III are appreciably smaller than the $c_{\mathrm{K}}$ values in Table I which range from 34 for $\mathrm{Ag}$ to 116 for $\mathrm{Bi}$.

Figures 13 and 14 show expanded views of the lowenergy regions, from $X=0$ to $X=4$, of the Fano plots in Figs. 11 and 12. The dashed lines in Figs. 13 and 14 are, as before, linear fits to the $Y_{\text {Fano }}$ values from the calculated cross sections with Eq. (8) over energy regions, $E_{\min }$ to $E_{\max }$, where the deviations with respect to the solid lines are less than 5\%. Table IV shows values of the derived Bethe parameters $b_{\mathrm{L}}$ and $c_{\mathrm{L}}$ and their one-standard-deviation uncertainties from the fits for each element, the values of $E_{\min }$ and $E_{\max }$, and the corresponding overvoltage values, $U_{\min }$ and $U_{\max }$. We see that $b_{\mathrm{L}}$ decreases from about 0.74 for $\mathrm{Ag}$ to 0.68 for $\mathrm{U}$ while $c_{\mathrm{L}}$ increases slightly from about 1.08 for $\mathrm{Ag}$ to about 1.30 for $\mathrm{U}$. The $b_{\mathrm{L}}$ values in Table IV are larger than the corresponding values in Table III (by around a factor of 2 for $\mathrm{Ta}, \mathrm{Pb}, \mathrm{Bi}$, and $\mathrm{U}$ ) while the values of $c_{\mathrm{L}}$ in Table IV are more than an order of magnitude smaller than those in Table III. We also see that the values of $b_{\mathrm{L}}$ and $c_{\mathrm{L}}$ in Table IV are roughly comparable with the values of $b_{\mathrm{K}}$ and $c_{\mathrm{K}}$ in Table II for the elements Ag through $\mathrm{Bi}$.

We also show Fano plots in Figs. 11 and 13 based on calculations and measurements of $\mathrm{L}_{3}$-subshell ionization cross sections for $\mathrm{Xe}(Z=54)$. We found values of the Bethe parameters, $b_{\mathrm{L} 3}$ and $c_{\mathrm{L} 3}$, in the asymptotic high-energy region in Fig. 11 to be 0.410 and 20.7, respectively, $E_{\min }=292.9 \mathrm{keV}$, 

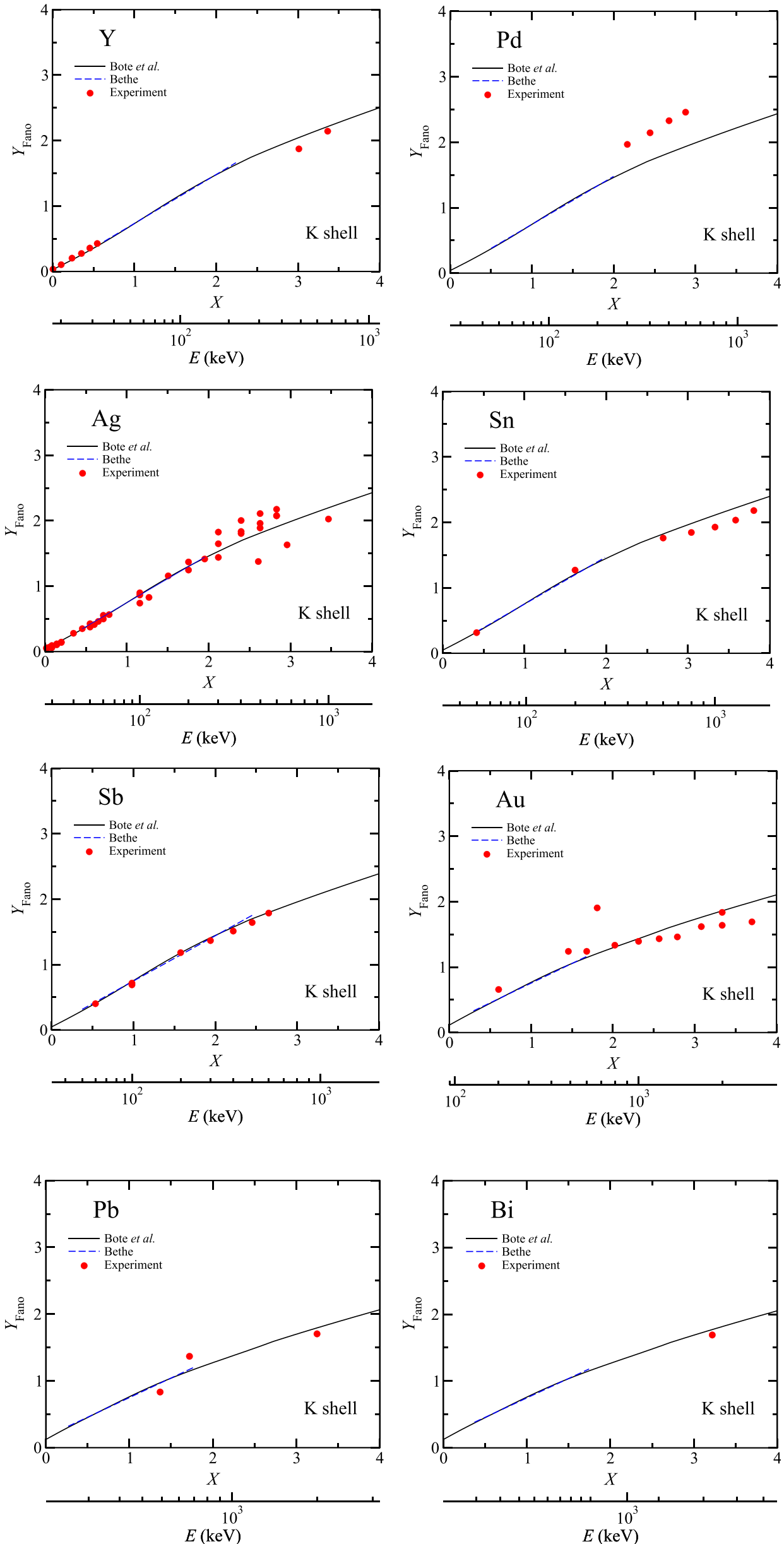
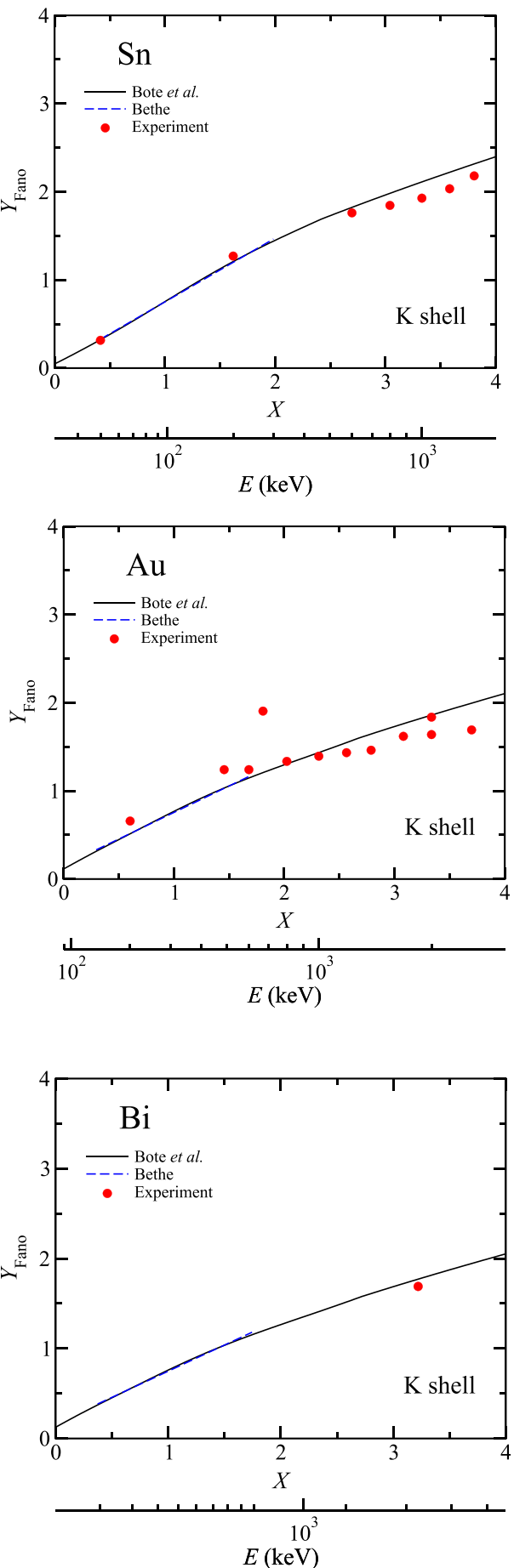

FIG. 9. Expanded view of the Fano plots for $\mathrm{Y}, \mathrm{Pd}, \mathrm{Ag}, \mathrm{Sn}, \mathrm{Sb}$, and $\mathrm{Au}$ in Fig. 4 from $X=0$ to $X=4$; see caption to Fig. 6 .
FIG. 10. Expanded view of the Fano plots for $\mathrm{Pb}$ and $\mathrm{Bi}$ in Fig. 5 from $X=0$ to $X=4$; see caption to Fig. 6 . 
TABLE II. Values of the Bethe parameters, $b_{\mathrm{K}}$ and $c_{\mathrm{K}}$, and their one-standard-deviation uncertainties derived from fits with Eq. (8) in the low-energy linear regions of the Fano plots with K-shell ionization cross sections in Figs. 6-10. We also show the minimum and maximum kinetic energies, $E_{\min }$ and $E_{\text {max }}$, at which the deviation of the fitted lines in the Fano plots of Figs. 6-10 are less than $5 \%$ and the corresponding values of the overvoltage, $U_{\text {min }}$ and $U_{\text {max }}$.

\begin{tabular}{|c|c|c|c|c|c|c|c|}
\hline Element & $Z$ & $b_{\mathrm{K}}$ & $c_{\mathrm{K}}$ & $E_{\min }(\mathrm{keV})$ & $E_{\max }(\mathrm{keV})$ & $U_{\min }$ & $U_{\max }$ \\
\hline $\mathrm{C}$ & 6 & $0.8058 \pm 0.0009$ & $0.796 \pm 0.002$ & 0.66 & 6.21 & 2.3 & 21.8 \\
\hline $\mathrm{N}$ & 7 & $0.8396 \pm 0.0009$ & $0.822 \pm 0.002$ & 0.90 & 8.07 & 2.2 & 19.7 \\
\hline $\mathrm{O}$ & 8 & $0.8383 \pm 0.0009$ & $0.824 \pm 0.002$ & 1.18 & 10.5 & 2.2 & 19.3 \\
\hline $\mathrm{Ne}$ & 10 & $0.8412 \pm 0.0009$ & $0.832 \pm 0.002$ & 1.88 & 16.9 & 2.2 & 19.4 \\
\hline $\mathrm{Al}$ & 13 & $0.812 \pm 0.001$ & $0.860 \pm 0.002$ & 3.26 & 28.0 & 2.1 & 17.9 \\
\hline $\mathrm{Si}$ & 14 & $0.804 \pm 0.001$ & $0.868 \pm 0.002$ & 3.80 & 32.6 & 2.1 & 17.7 \\
\hline $\mathrm{Ar}$ & 18 & $0.791 \pm 0.001$ & $0.894 \pm 0.002$ & 6.31 & 53.3 & 2.0 & 16.6 \\
\hline $\mathrm{Ca}$ & 20 & $0.781 \pm 0.001$ & $0.905 \pm 0.002$ & 7.82 & 66.1 & 1.9 & 16.4 \\
\hline $\mathrm{Ti}$ & 22 & $0.775 \pm 0.001$ & $0.914 \pm 0.002$ & 9.55 & 80.7 & 1.9 & 16.2 \\
\hline $\mathrm{Cr}$ & 24 & $0.770 \pm 0.001$ & $0.921 \pm 0.002$ & 11.5 & 95.5 & 1.9 & 15.9 \\
\hline Mn & 25 & $0.769 \pm 0.001$ & $0.926 \pm 0.002$ & 12.4 & 104.7 & 1.9 & 16.0 \\
\hline $\mathrm{Fe}$ & 26 & $0.767 \pm 0.001$ & $0.929 \pm 0.002$ & 13.4 & 113.1 & 1.9 & 15.9 \\
\hline $\mathrm{Ni}$ & 28 & $0.764 \pm 0.001$ & $0.936 \pm 0.002$ & 15.6 & 129.8 & 1.9 & 15.6 \\
\hline $\mathrm{Cu}$ & 29 & $0.763 \pm 0.001$ & $0.939 \pm 0.002$ & 16.9 & 138.0 & 1.9 & 15.4 \\
\hline $\mathrm{Zn}$ & 30 & $0.762 \pm 0.001$ & $0.943 \pm 0.002$ & 17.9 & 146.8 & 1.9 & 15.4 \\
\hline $\mathrm{Ga}$ & 31 & $0.760 \pm 0.001$ & $0.947 \pm 0.002$ & 19.3 & 156.1 & 1.9 & 15.1 \\
\hline $\mathrm{Ge}$ & 32 & $0.758 \pm 0.001$ & $0.951 \pm 0.002$ & 20.6 & 166.0 & 1.9 & 14.9 \\
\hline $\mathrm{Se}$ & 34 & $0.756 \pm 0.001$ & $0.959 \pm 0.002$ & 23.3 & 182.0 & 1.8 & 14.4 \\
\hline $\mathrm{Y}$ & 39 & $0.747 \pm 0.001$ & $0.981 \pm 0.002$ & 30.2 & 225.6 & 1.8 & 13.2 \\
\hline $\mathrm{Pd}$ & 46 & $0.734 \pm 0.001$ & $1.016 \pm 0.003$ & 41.7 & 284.0 & 1.7 & 11.7 \\
\hline $\mathrm{Ag}$ & 47 & $0.732 \pm 0.001$ & $1.021 \pm 0.003$ & 43.7 & 292.9 & 1.7 & 11.5 \\
\hline $\mathrm{Sn}$ & 50 & $0.724 \pm 0.002$ & $1.038 \pm 0.003$ & 48.6 & 321.1 & 1.7 & 11.0 \\
\hline $\mathrm{Sb}$ & 51 & $0.722 \pm 0.002$ & $1.043 \pm 0.003$ & 50.9 & 326.1 & 1.7 & 10.7 \\
\hline $\mathrm{Au}$ & 79 & $0.601 \pm 0.002$ & $1.292 \pm 0.006$ & 138.0 & 670.9 & 1.7 & 8.3 \\
\hline $\mathrm{Pb}$ & 82 & $0.587 \pm 0.002$ & $1.320 \pm 0.007$ & 146.8 & 702.5 & 1.7 & 8.0 \\
\hline $\mathrm{Bi}$ & 83 & $0.581 \pm 0.002$ & $1.333 \pm 0.007$ & 153.7 & 713.4 & 1.7 & 7.9 \\
\hline
\end{tabular}

and $U_{\min }=61.2$. These values are similar to the corresponding values from the total L-shell ionization cross sections for neighboring elements in Table III. For the linear fit to the low-energy region for $\mathrm{Xe}$ in Fig. 13, we found $b_{\mathrm{L} 3}$ $=0.741 \pm 0.001, c_{\mathrm{L} 3}=1.165 \pm 0.003, E_{\min }=9.3 \mathrm{keV}, E_{\max }$ $=89.8 \mathrm{keV}, U_{\min }=1.9$, and $U_{\max }=18.8$. These values are also similar to the corresponding values in Table IV derived from total L-shell ionization cross sections.

Finally, we note that the linear regions of the lowenergy Fano plots in Figs. 13 and 14 range from $U_{\min }=1.5$ to $U_{\max } \approx 19$ for Ag to $U_{\min }=1.9$ to $U_{\max } \approx 12$ for $\mathrm{U}$. We also see that the values of $U_{\min }$ in Table III for the highenergy Fano plots in Figs. 11 and 12 range from about 60 for Ag to about 162 for U. The Fano plots in Figs. 11 and 12 thus change their slopes (between the two linear regions) over a smaller range of $X$ than for the Fano plots in Figs. 1-5.

\section{M-shell ionization cross sections}

Figure 15 shows Fano plots based on total crosssections for $\mathrm{M}$-shell ionization, $\sigma_{\mathrm{M}}$, in $\mathrm{Au}, \mathrm{Pb}$, and $\mathrm{Bi}$. As for Figs. 1-14, we have plotted $Y_{\text {Fano }}$ from Eq. (7) versus $X$ from Eq. (6). The solid lines show $Y_{\text {Fano }}$ with the calculated cross sections of Bote et al. ${ }^{7,8}$ and the solid circles show $Y_{\text {Fano }}$ with the preferred measured cross sections of Llovet et al. (Tables 4 and 11 of Ref. 9). Values of $Y_{\text {Fano }}$ from Eq. (7) were calculated with the average M-shell binding energies determined from the M-subshell binding energies of Williams ${ }^{12}$ for each element that were weighted by the corresponding subshell occupancy numbers using an equation analogous to Eq. (11b) for L-shell ionization. The abscissas in Figs. 11 and 12 also show the electron kinetic energy. As before, the Fano plots extend from the ionization threshold $(X=0)$ to $X=20$ where the maximum energy is between $1 \mathrm{GeV}$ and $2 \mathrm{GeV}$.

Like Figs. 1-5, 11, and 12, the Fano plots in Fig. 15 show two linear regions. We have made linear fits to the $Y_{\text {Fano }}$ values from the calculated cross sections with Eq. (8) in the asymptotic high-energy linear regions of each Fano plot. These fits (dashed lines) have been extrapolated to a minimum energy, $E_{\text {min }}$, at which the deviations from the solid lines become $5 \%$. Table $\mathrm{V}$ shows the Bethe parameters, $b_{\mathrm{M}}$ and $c_{\mathrm{M}}$, from each fit, the values of $E_{\text {min }}$, and the corresponding values of $U_{\min }$. The values of $b_{\mathrm{M}}$ in Table $\mathrm{V}$ for $\mathrm{Pb}$ and $\mathrm{Bi}$ are about 0.53 , appreciably larger than the $b_{\mathrm{L}}$ values for these elements in Table III (0.33). In contrast, the $c_{\mathrm{M}}$ values in Table $\mathrm{V}$ for $\mathrm{Pb}$ and $\mathrm{Bi}$ (about 8.8) are much smaller than the $c_{\mathrm{L}}$ values for these elements in Table III (about 51).

Figure 16 shows expanded views of the low-energy regions, from $X=0$ to $X=4$, of the Fano plots in Fig. 15. As previously mentioned, the dashed lines in Fig. 16 are linear fits to the $Y_{\text {Fano }}$ values from the calculated cross sections with Eq. (8) over energy regions, $E_{\min }$ to $E_{\max }$, where the deviations with respect to the solid line are less than $5 \%$. Table VI shows values of the resulting Bethe parameters, $b_{\mathrm{M}}$ and $c_{\mathrm{M}}$, and their one-standard-deviation uncertainties as 

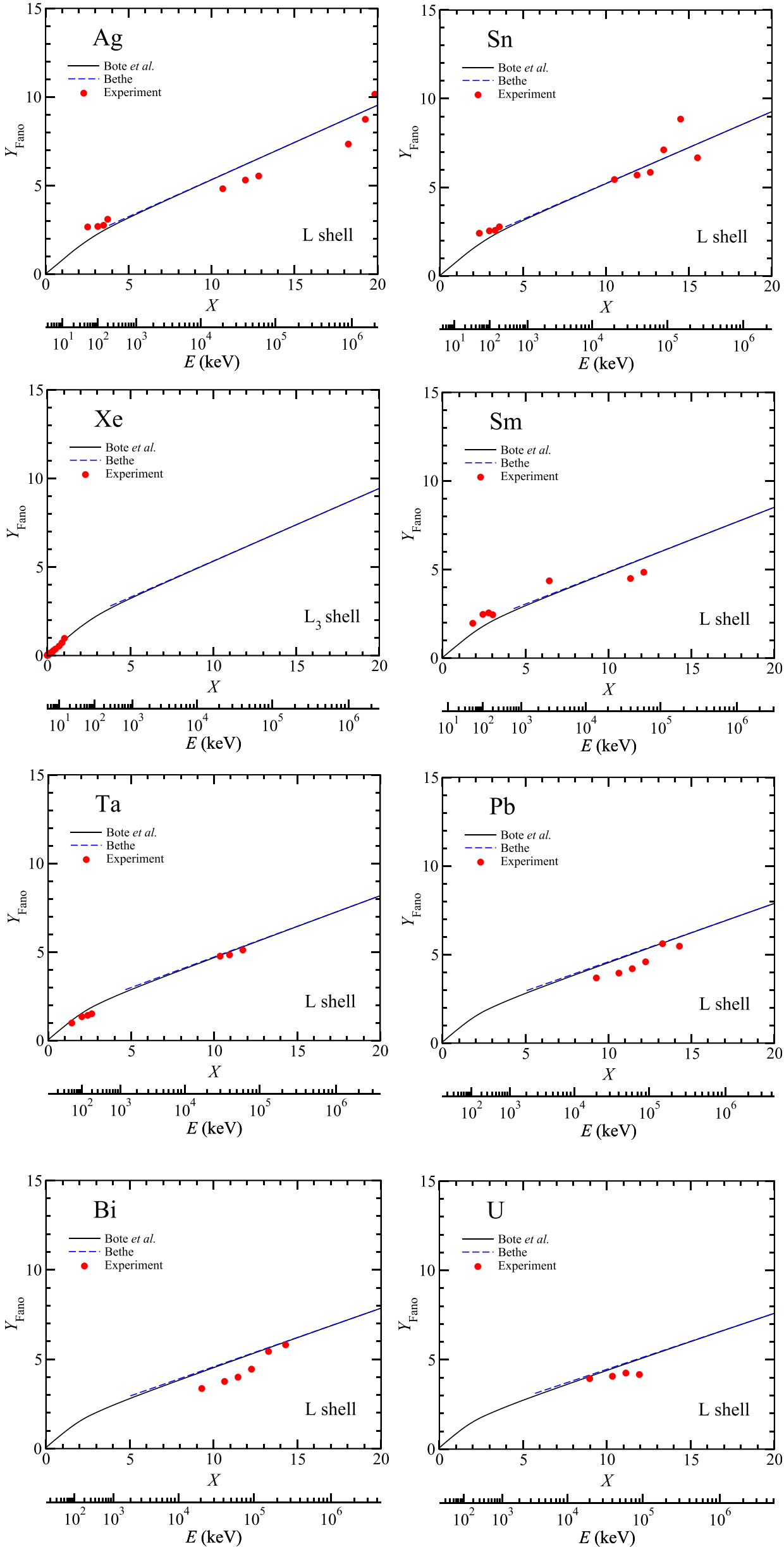

FIG. 11. Fano plots for $\mathrm{Ag}, \mathrm{Sn}, \mathrm{Xe}$, $\mathrm{Sm}, \mathrm{Ta}$, and $\mathrm{Pb}$ (solid lines) based on total L-shell ionization cross sections calculated by Bote et al. ${ }^{7,8}$ and Fano plot for Xe (solid line) based on the calculated $\mathrm{L}_{3}$-subshell ionization cross sections of Bote et al. ${ }^{7,8}$ In these plots, $Y_{\text {Fano }}$ from Eq. (7) is plotted against $X$ from Eq. (6). The abscissa also shows the electron kinetic energy, $E$. The dashed lines show linear fits to the $Y_{\text {Fano }}$ values from the calculated cross sections with Eq. (8) in the asymptotic high-energy region of the Fano plots. The dashed lines have been extrapolated to a lower energy at which the deviation from the solid lines is $5 \%$. The solid circles show values of $Y_{\text {Fano }}$ calculated from the preferred measured total $\mathrm{L}$-shell or $\mathrm{L}_{3}$-subshell ionization cross sections of Llovet et al. (Tables 3 and 9 of Ref. 9).

FIG. 12. Fano plots for Bi and U; see caption to Fig. 11. 
TABLE III. Values of the Bethe parameters, $b_{\mathrm{L}}$ and $c_{\mathrm{L}}$, derived from the linear fits with Eq. (8) in the high-energy asymptotic regions of the Fano plots in Figs. 11 and 12 for $\mathrm{Ag}, \mathrm{Sn}, \mathrm{Sm}, \mathrm{Ta}, \mathrm{Pb}, \mathrm{Bi}$, and $\mathrm{U}$ with total $\mathrm{L}$-shell ionization cross sections. We also show the minimum kinetic energy, $E_{\min }$, at which the deviation of the fitted lines in the Fano plots of Figs. 11 and 12 becomes $5 \%$ and the corresponding value of the overvoltage, $U_{\mathrm{min}}$.

\begin{tabular}{lccccc}
\hline \hline Element & $Z$ & $b_{\mathrm{L}}$ & $c_{\mathrm{L}}$ & $E_{\text {min }}(\mathrm{keV})$ & $U_{\text {min }}$ \\
\hline $\mathrm{Ag}$ & 47 & 0.419 & 15.4 & 202.6 & 57.8 \\
$\mathrm{Sn}$ & 50 & 0.405 & 17.9 & 259.0 & 62.9 \\
$\mathrm{Sm}$ & 62 & 0.364 & 29.1 & 621.3 & 87.3 \\
$\mathrm{Ta}$ & 73 & 0.346 & 38.6 & 1148 & 107.9 \\
$\mathrm{~Pb}$ & 82 & 0.330 & 50.6 & 1848 & 129.4 \\
$\mathrm{Bi}$ & 83 & 0.328 & 52.2 & 1935 & 131.3 \\
$\mathrm{U}$ & 92 & 0.313 & 70.1 & 3114 & 161.7 \\
\hline \hline
\end{tabular}

well as the values of $E_{\min }, E_{\max }, U_{\min }$, and $U_{\max }$. We see that the values of $b_{\mathrm{M}}$ in Table $\mathrm{VI}$ for $\mathrm{Pb}$ are $\mathrm{Bi}$ (about 0.790 ) are larger than the $b_{\mathrm{L}}$ values for these elements in Table IV (0.690) while the $c_{\mathrm{M}}$ values in Table VI for the same elements (about 1.27) are essentially the same as the corresponding $c_{\mathrm{L}}$ values in Table IV (1.24).

The linear regions of the low-energy Fano plots in Fig. 16 extend from $U_{\min }=2.1$ for $\mathrm{Au}, \mathrm{Pb}$, and $\mathrm{Bi}$ to values of $U_{\max }$ ranging from about 32 for $\mathrm{Au}$ to about 29 for Bi. The values of $U_{\min }$ for the high-energy Fano plots in Fig. 15 are about 38. Unlike the L-shell Fano plots in Figs. 11 and 12, the M-shell Fano plots in Fig. 15 change their slopes between the two linear regions over a narrow range of $X$.
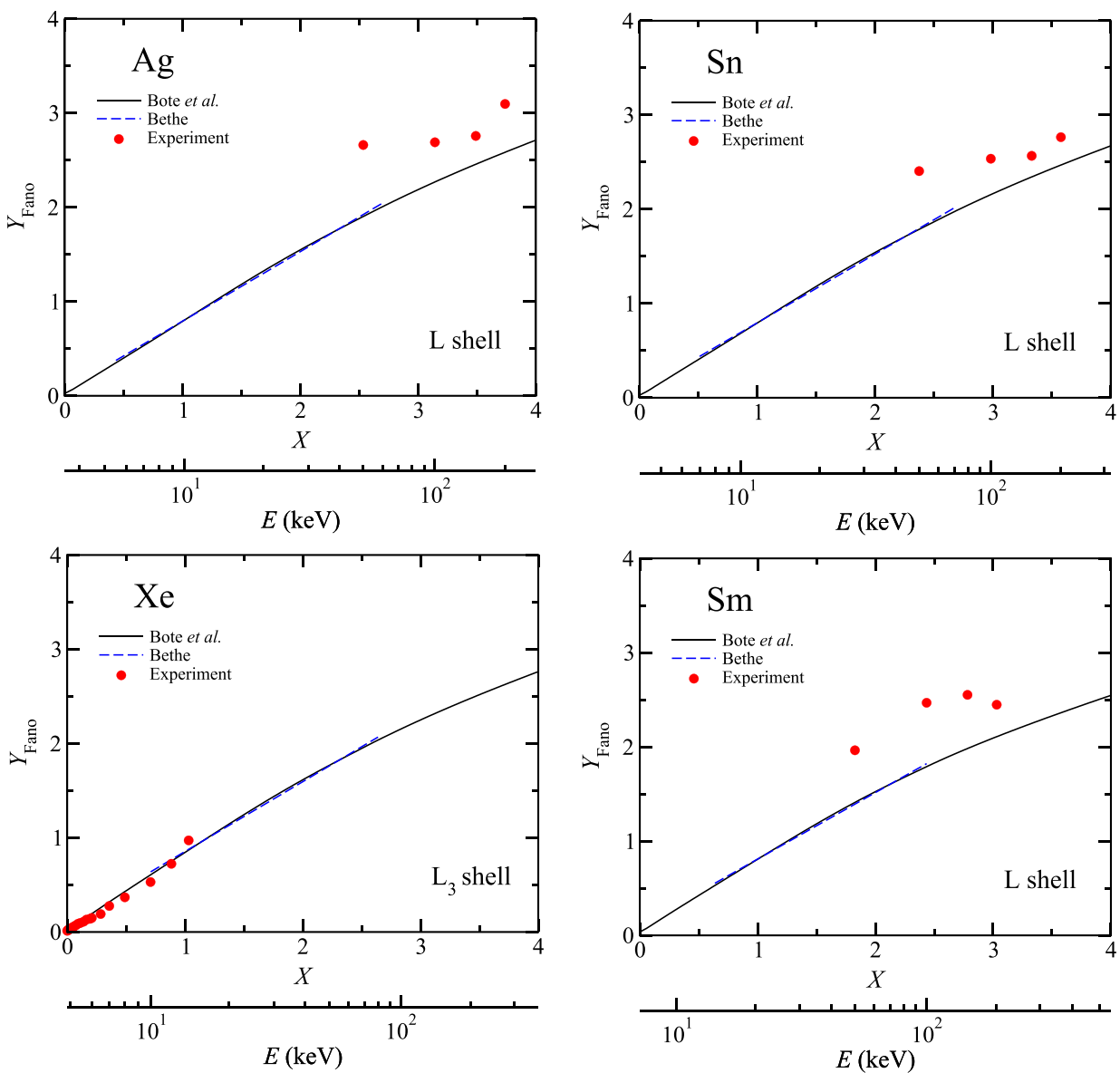

FIG. 13. Expanded view of the Fano plots for $\mathrm{Ag}, \mathrm{Sn}, \mathrm{Xe}, \mathrm{Sm}, \mathrm{Ta}$, and $\mathrm{Pb}$ in Fig. 11 (solid lines) from $X=0$ to $X=4$. The abscissa also shows the electron kinetic energy, $E$. The dashed lines show linear fits to the $Y_{\text {Fano }}$ values from the calculated cross sections with Eq. (8) over the energy range, $E_{\min }$ to $E_{\max }$, where the deviations from the solid lines are less than 5\%. The solid circles show values of $Y_{\text {Fano }}$ calculated from the measured total Lshell ionization cross sections (or, for $\mathrm{Xe}$, the preferred measured $\mathrm{L}_{3}$-subshell ionization cross sections) of Llovet et al. (Tables 3 and 9 of Ref. 9).
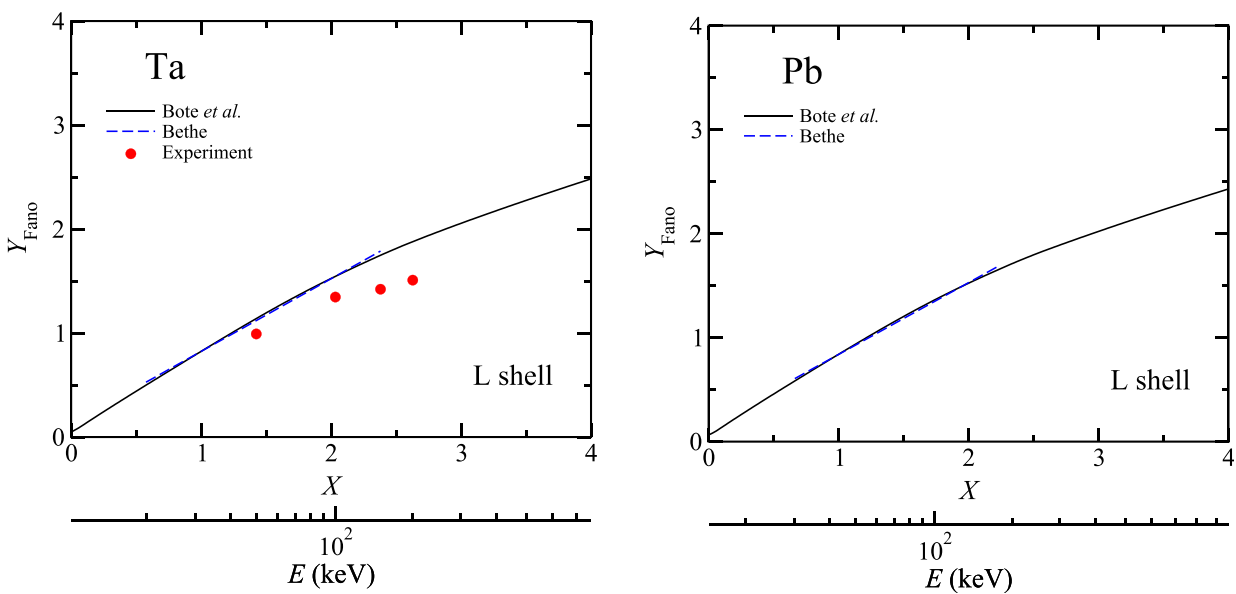

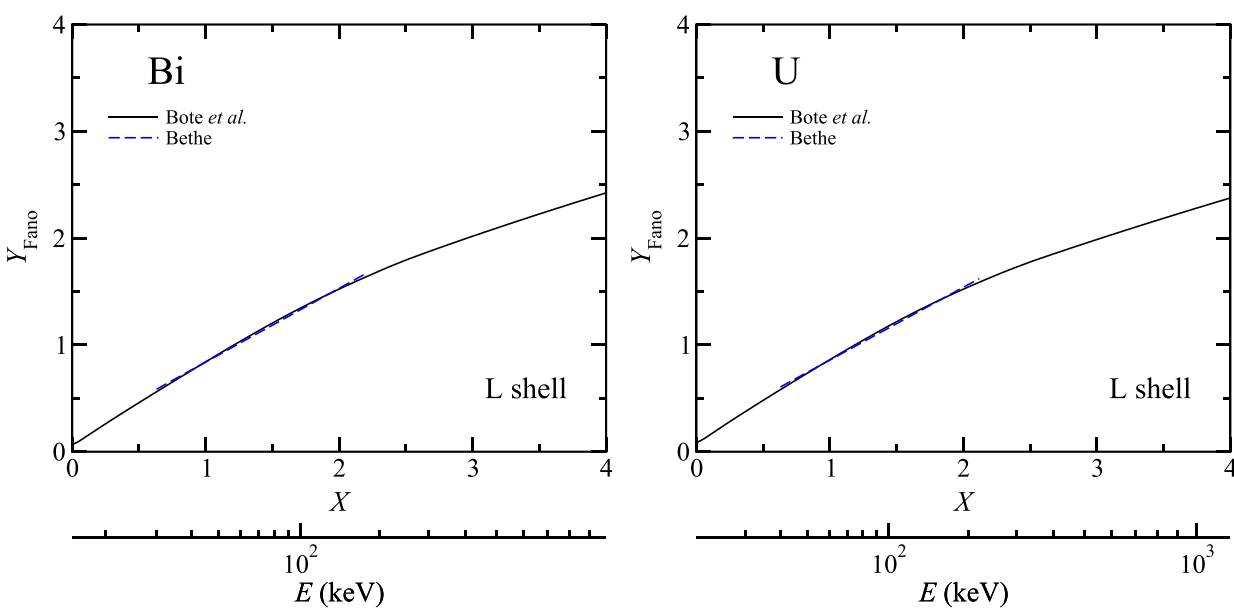

FIG. 14. Expanded view of the Fano plots for $\mathrm{Bi}$ and $\mathrm{U}$ in Fig. 12 from $X=0$ to $X=4$; see caption to Fig. 13 .

\section{DISCUSSION}

Figure 17 shows plots of the Bethe parameters $b_{i}$ and $\mathrm{c}_{i}$ $(i=\mathrm{K}, \mathrm{L}$, or $\mathrm{M})$ as a function of $Z$ from fits with Eq. (8) in the high- and low-energy regions of the Fano plots in Figs. 1-16. The top panels of Fig. 17 show plots of $b_{i}$ and $c_{i}$ from the fits in the high-energy regions of the Fano plots shown in Figs. 1-5 for K-shell ionization, Figs. 11 and 12 for L-shell ionization, and Fig. 15 for M-shell ionization, as listed in Tables I, III, and V. We see that the values of $b_{\mathrm{K}}$ (top-left panel) decrease monotonically from about 0.52 for $\mathrm{C}, \mathrm{N}, \mathrm{O}$, and $\mathrm{Ne}$ to about 0.28 for $\mathrm{Au}, \mathrm{Pb}$, and $\mathrm{Bi}$. The values of $b_{\mathrm{L}}$ in the top-left panel, decreasing from about 0.41 for $\mathrm{Ag}$ and $\mathrm{Sn}$ to about 0.32 for $\mathrm{Pb}, \mathrm{Bi}$, and $\mathrm{U}$, are about $15 \%$ larger than the $b_{\mathrm{K}}$ values for medium- $Z$ ( $\mathrm{Ag}$ and $\mathrm{Sn}$ ) and high- $Z$ elements $(\mathrm{Pb}$ and $\mathrm{Bi})$. In contrast, the values of $b_{\mathrm{M}}$ in the top-left panel of Fig. 17 (about 0.53 for $\mathrm{Au}, \mathrm{Pb}$, and $\mathrm{Bi}$ ) are about $90 \%$ larger than the $b_{\mathrm{K}}$ values for the same elements (0.28).

The values of $c_{\mathrm{K}}$ from the high-energy fits (top-right panel of Fig. 17) increase monotonically with $Z$ from about 5.9 for $\mathrm{C}$ to 116 for $\mathrm{Bi}$. The values of $c_{\mathrm{L}}$, ranging from about 15 for $\mathrm{Ag}$ to about 70 for $\mathrm{U}$, are roughly half of the values of $c_{\mathrm{K}}$ for medium- $Z$ and high- $Z$ elements. Finally, the values of $c_{\mathrm{M}}$, between 7.8 and 8.9 for $\mathrm{Au}, \mathrm{Pb}$, and $\mathrm{Bi}$,

TABLE IV. Values of the Bethe parameters, $b_{\mathrm{L}}$ and $c_{\mathrm{L}}$, and their one-standard-deviation uncertainties derived from fits with Eq. (8) in the low-energy linear regions of the Fano plots with total L-shell ionization cross sections in Figs. 13 and 14. We also show the minimum and maximum kinetic energies, $E_{\min }$ and $E_{\max }$, at which the deviation of the fitted lines in the Fano plots of Figs. 13 and 14 are less than 5\% and the corresponding values of the overvoltage, $U_{\min }$ and $U_{\max }$.

\begin{tabular}{|c|c|c|c|c|c|c|c|}
\hline Element & $Z$ & $b_{\mathrm{L}}$ & $c_{\mathrm{L}}$ & $\begin{array}{l}E_{\min } \\
(\mathrm{keV})\end{array}$ & $\begin{array}{l}E_{\max } \\
(\mathrm{keV})\end{array}$ & $U_{\min }$ & $U_{\max }$ \\
\hline $\mathrm{Ag}$ & 47 & $0.737 \pm 0.001$ & $1.078 \pm 0.002$ & 5.29 & 65.1 & 1.5 & 18.5 \\
\hline Sn & 50 & $0.729 \pm 0.001$ & $1.096 \pm 0.002$ & 6.51 & 72.4 & 1.6 & 17.6 \\
\hline $\mathrm{Sm}$ & 62 & $0.706 \pm 0.001$ & $1.157 \pm 0.003$ & 12.6 & 109.6 & 1.8 & 15.4 \\
\hline $\mathrm{Ta}$ & 73 & $0.699 \pm 0.001$ & $1.195 \pm 0.004$ & 19.3 & 151.4 & 1.8 & 14.2 \\
\hline $\mathrm{Pb}$ & 82 & $0.690 \pm 0.001$ & $1.240 \pm 0.004$ & 27.1 & 187.6 & 1.9 & 13.1 \\
\hline $\mathrm{Bi}$ & 83 & $0.691 \pm 0.001$ & $1.240 \pm 0.004$ & 27.5 & 190.5 & 1.9 & 12.9 \\
\hline $\mathrm{U}$ & 92 & $0.681 \pm 0.002$ & $1.297 \pm 0.005$ & 37.4 & 229.1 & 1.9 & 11.9 \\
\hline
\end{tabular}

are about 13 times smaller than the values of $c_{\mathrm{K}}$ for the same elements.

We turn now to the values of $b_{i}$ and $c_{i}$ in the bottom panels of Fig. 17 that were obtained from the fits in the lowenergy regions of the Fano plots shown in Figs. 6-10 for K-shell ionization, Figs. 13 and 14 for L-shell ionization, and Fig. 16 for M-shell ionization, as listed in Tables II, IV, and VI. The value of $b_{\mathrm{K}}$ (bottom-left panel) is 0.806 for $\mathrm{C}$, increases to about 0.84 for $\mathrm{N}, \mathrm{O}$, and $\mathrm{Ne}$, and then gradually decreases to 0.581 for $\mathrm{Bi}$. The values of $b_{\mathrm{L}}$ for $\mathrm{Ag}$ and $\mathrm{Sn}$ (about 0.73 ) are essentially the same as the values of $b_{\mathrm{K}}$ for the same elements. However, the values of $b_{\mathrm{L}}$ for $\mathrm{Pb}$ and $\mathrm{Bi}$ (about 0.69) are around 17\% larger than the values of $b_{\mathrm{K}}$ for the same elements (about 0.59). We see that the values of $b_{\mathrm{M}}$ for $\mathrm{Au}, \mathrm{Pb}$, and $\mathrm{Bi}$ (about 0.79 ) are about 34\% larger than the $b_{\mathrm{K}}$ values for the same elements (about 0.59).

Overall, the $b_{i}$ values from the low-energy fits range from between 0.806 for $\mathrm{C}$ and about 0.84 for $\mathrm{N}, \mathrm{O}$, and $\mathrm{Ne}$ (for K-shell ionization) to about 0.7 as a rough average of the values of $b_{\mathrm{K}}, b_{\mathrm{L}}$, and $b_{\mathrm{M}}$ for the high- $Z$ elements. In comparison, the $b_{i}$ values from the high-energy fits range from about 0.52 for $\mathrm{C}, \mathrm{N}, \mathrm{O}$, and $\mathrm{Ne}$ to $b_{\mathrm{K}}$ values of about 0.28 for $\mathrm{Au}, \mathrm{Pb}$, and $\mathrm{Bi}$, to $b_{\mathrm{L}}$ values of about 0.32 for $\mathrm{Pb}, \mathrm{Bi}$, and $\mathrm{U}$, and to $b_{\mathrm{M}}$ values of about 0.53 for $\mathrm{Au}, \mathrm{Pb}$, and $\mathrm{Bi}$. The $b_{\mathrm{K}}$ values from the low-energy fits are thus about $60 \%$ larger than those from the high-energy fits for the low- $Z$ elements, the $b_{\mathrm{L}}$ values from the low-energy fits are roughly double those from the high-energy fits for the medium- and high- $Z$ elements, and the $b_{\mathrm{M}}$ values from the low-energy fits are about $50 \%$ larger than those from the high-energy fits.

The values of $c_{\mathrm{K}}$ from the low-energy fits (bottom-right panel of Fig. 17) increase monotonically with $Z$ from 0.796 for $\mathrm{C}$ to 1.043 for $\mathrm{Sb}$ but are then about 1.3 for $\mathrm{Au}, \mathrm{Pb}$, and Bi. The values of $c_{\mathrm{L}}$ range from 1.078 for $\mathrm{Ag}$ to 1.297 for $\mathrm{U}$ while the values of $c_{\mathrm{M}}$ are about 1.26 for $\mathrm{Au}, \mathrm{Pb}$, and $\mathrm{Bi}$. These $c_{\mathrm{i}}$ values are appreciably less than those obtained from the high-energy fits, which can be larger by between roughly one to two orders of magnitude.

The values of $b_{i}$ from the high-energy fits (top-left panel of Fig. 17) range from about $0.28\left(b_{\mathrm{K}}\right.$ values for $\mathrm{Au}, \mathrm{Pb}$, and $\mathrm{Bi}$ ) to about 0.53 ( $b_{\mathrm{K}}$ value for $\mathrm{N}$ and $b_{\mathrm{M}}$ values for $\mathrm{Au}, \mathrm{Pb}$, and $\mathrm{Bi}$ ). This range corresponds to that estimated by Bethe ${ }^{1}$ 

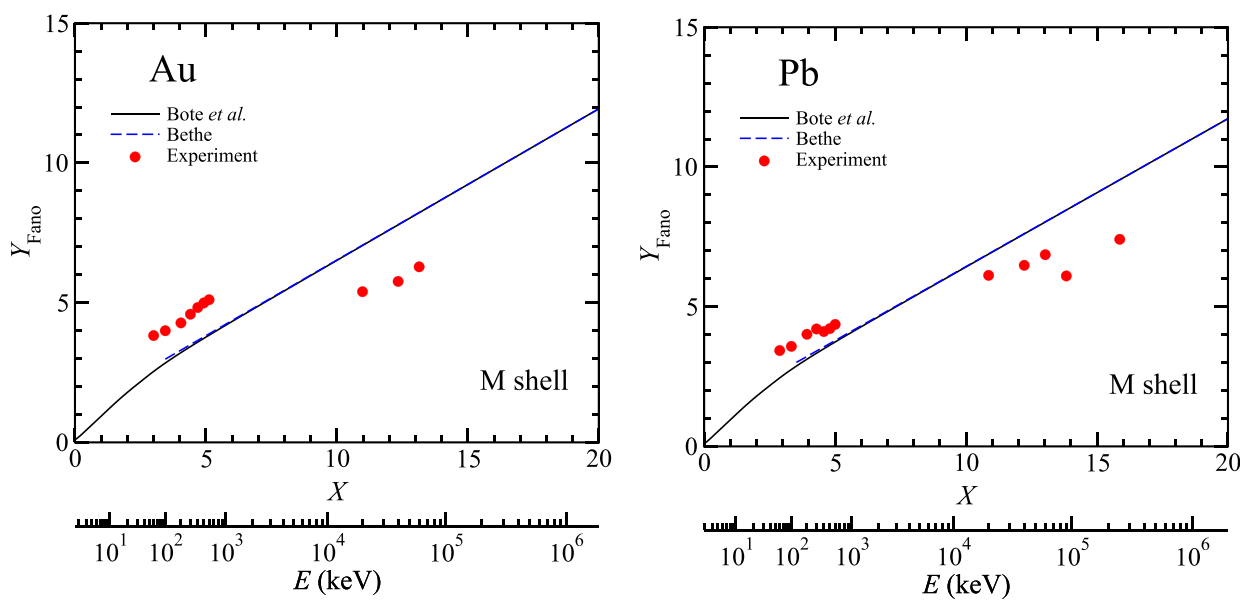

FIG. 15. Fano plots for $\mathrm{Au}, \mathrm{Pb}$, and $\mathrm{Bi}$ (solid lines) based on total M-shell ionization cross sections calculated by Bote et al. ${ }^{7,8}$ in which $Y_{\text {Fano }}$ from Eq. (7) is plotted against $X$ from Eq. (6). The abscissa also shows the electron kinetic energy, $E$. The dashed lines show linear fits to the $Y_{\text {Fano }}$ values from the calculated cross sections with Eq. (8) in the asymptotic high-energy region of the Fano plots. The dashed lines have been extrapolated to a lower energy at which the deviation from the solid lines is $5 \%$. The solid circles show values of $Y_{\text {Fano }}$ calculated from the preferred measured total M-shell ionization cross sections of Llovet et al. (Tables 4 and 11 of Ref. 9).

(0.2 to 0.6$)$ with hydrogenic wave functions. However, the values of $c_{\mathrm{i}}$ from the high-energy fits (top-right panel of Fig. 17), between 5 and 116, are generally much larger than the value estimated by Bethe (about 4).

We now comment briefly on the measured cross sections for K-shell ionization shown as solid circles in Figs. 1-5. For some of the measured $\mathrm{K}$-shell ionization cross sections (e.g., Si in Fig. 1; Ca, Cr, and $\mathrm{Mn}$ in Fig. 2; Ni, Cu, and $\mathrm{Ge}$ in Fig. 3; and Y, Ag, Sn, and Au in Fig. 4), there are sufficient measurements in both the low-energy and high-energy regions of the Fano plots to define adequately the two expected linear regions. ${ }^{11}$ These two regions have not been separately observed before because cross-section measurements made in a particular laboratory were generally made over a limited range of incident electron energies. Other measured K-shell ionization cross sections (e.g., C, N, O,

TABLE V. Values of the Bethe parameters, $b_{\mathrm{M}}$ and $c_{\mathrm{M}}$, derived from the linear fits with Eq. (8) in the high-energy asymptotic regions of the Fano plots in Fig. 15 for $\mathrm{Au}, \mathrm{Pb}$, and $\mathrm{Bi}$ with total $\mathrm{M}$-shell ionization cross sections. We also show the minimum kinetic energy, $E_{\min }$, at which the deviation of the fitted lines in the Fano plots of Fig. 15 becomes 5\% and the corresponding value of the overvoltage, $U_{\min }$.

\begin{tabular}{lccccc}
\hline \hline Element & $Z$ & $\mathrm{~b}_{\mathrm{M}}$ & $\mathrm{c}_{\mathrm{M}}$ & $E_{\min }(\mathrm{keV})$ & $U_{\min }$ \\
\hline $\mathrm{Au}$ & 79 & 0.541 & 7.79 & 97.0 & 37.5 \\
$\mathrm{~Pb}$ & 82 & 0.529 & 8.63 & 111.3 & 38.3 \\
$\mathrm{Bi}$ & 83 & 0.526 & 8.92 & 118.4 & 39.2 \\
\hline \hline
\end{tabular}

and $\mathrm{Ne}$ in Fig. 1; Ti and Fe in Fig. 2; Ga in Fig. 3; and $\mathrm{Sb}$ in Fig. 4) were made with incident energies that occurred only in the low-energy regions of the Fano plots. There are fewer measured cross sections for L-shell ionization in Figs. 11 and 12 and for M-shell ionization in Fig. 15 than for K-shell ionization and it is consequently harder to discern, for any one element, the existence of two linear regions in the Fano plots. The calculated ionization cross sections of Bote et $a l .^{7,8}$ were thus invaluable not only for providing a framework for the evaluation of the measured cross sections ${ }^{9}$ but also for clearly indicating, by the Fano plots shown here, the existence of two linear regions in the Fano plots for each element.

\section{SUMMARY}

We analyzed the calculated cross sections of Bote et al $^{7,8}$ for $\mathrm{K}-$, L-, and M-shell ionization by electron impact to determine the energy ranges over which these cross sections are consistent with the Bethe equation for inner-shell ionization. ${ }^{1-3}$ The Bethe equation is a relatively simple analytical expression with two element-specific parameters, $b_{i}$ and $c_{i}$. The validity (or otherwise) of the Bethe equation for a particular set of calculated or measured ionization cross sections can be checked with a Fano plot $^{3}$ based on a linearized form of the Bethe equation. If such a plot is found to be linear for a specified energy range, the Bethe parameters, $b_{i}$ and $c_{i}$, can be determined. 

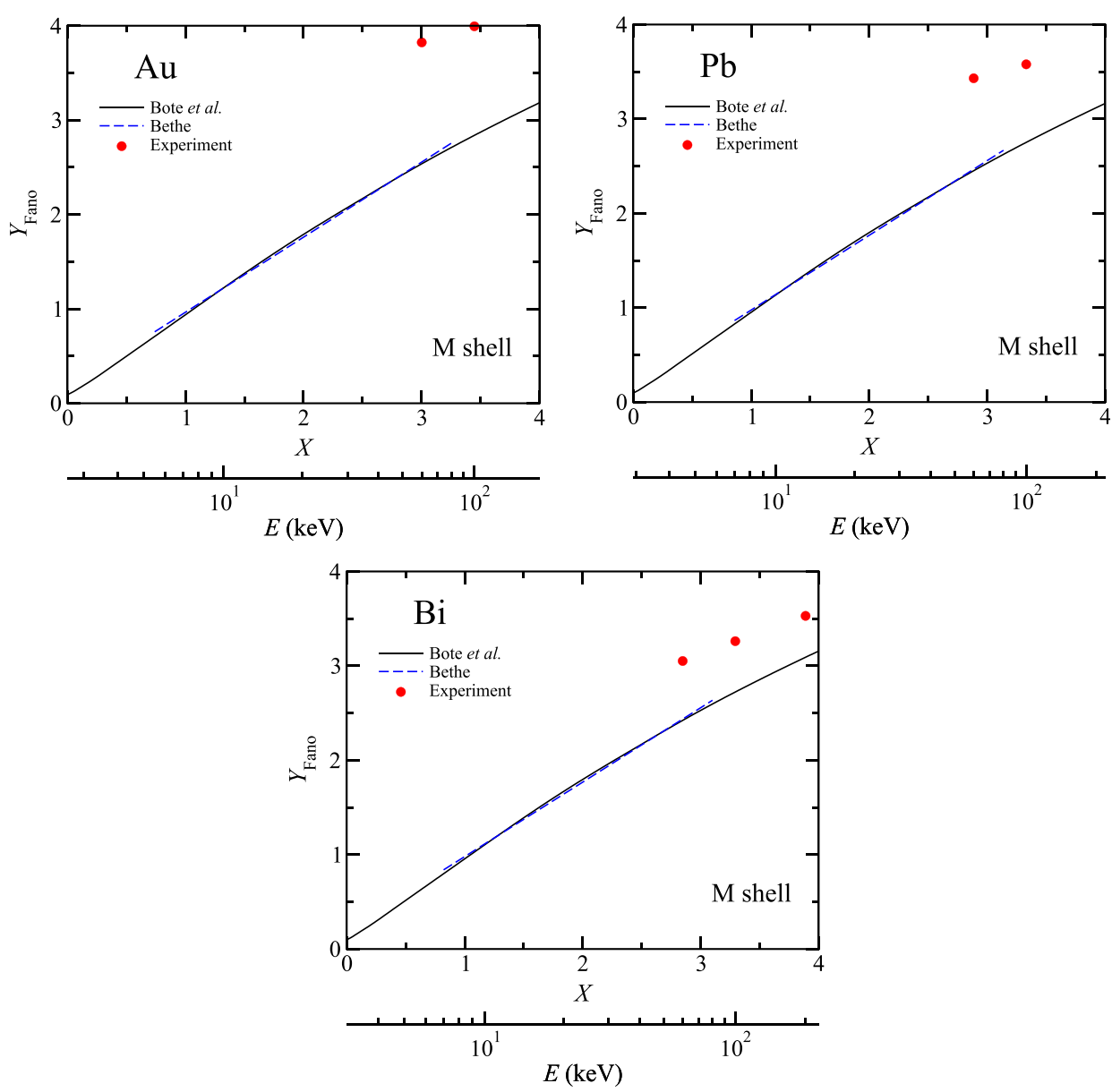

FIG. 16. Expanded views of the Fano plots for $\mathrm{Au}, \mathrm{Pb}$, and $\mathrm{Bi}$ in Fig. 15 (solid lines) from $X=0$ to $X=4$; see also caption to Fig. 15
Our analysis was performed with calculated ${ }^{7,8} \mathrm{~K}$-shell ionization cross sections for 26 elements $(\mathrm{C}, \mathrm{N}, \mathrm{O}, \mathrm{Ne}, \mathrm{Al}$, $\mathrm{Si}, \mathrm{Ar}, \mathrm{Ca}, \mathrm{Ti}, \mathrm{Cr}, \mathrm{Mn}, \mathrm{Fe}, \mathrm{Ni}, \mathrm{Cu}, \mathrm{Zn}, \mathrm{Ga}, \mathrm{Ge}, \mathrm{Se}, \mathrm{Y}, \mathrm{Pd}$, $\mathrm{Ag}, \mathrm{Sn}, \mathrm{Sb}, \mathrm{Au}, \mathrm{Pb}$, and $\mathrm{Bi}$ ), for total $\mathrm{L}$-shell ionization cross sections for seven elements ( $\mathrm{Ag}, \mathrm{Sn}, \mathrm{Sm}, \mathrm{Ta}, \mathrm{Pb}, \mathrm{Bi}$, and $\mathrm{U}$ ), with $\mathrm{L}_{3}$-subshell ionization cross sections of $\mathrm{Xe}$, and with total M-shell ionization cross sections of three elements ( $\mathrm{Au}$, $\mathrm{Pb}$, and $\mathrm{Bi})$. We have previously shown that the calculated cross sections for these elements and shells, available from the threshold energy for ionization to $1 \mathrm{GeV}$, agreed satisfactorily with sets of measured cross sections that were mutually consistent with each other and which varied with energy as expected by theory. ${ }^{9}$

Our Fano plots for each element and shell showed two linear regions as predicted by de Heer and Inokuti. ${ }^{11}$ For

TABLE VI. Values of the Bethe parameters, $b_{\mathrm{M}}$ and $c_{\mathrm{M}}$, and their onestandard-deviation uncertainties derived from fits with Eq. (8) in the lowenergy linear regions of the Fano plots with total M-shell ionization cross sections in Fig. 16. We also show the minimum and maximum kinetic energies, $E_{\min }$ and $E_{\max }$, at which the deviation of the fitted lines in the Fano plots of Fig. 16 are less than 5\% and the corresponding values of the overvoltage, $U_{\min }$ and $U_{\max }$.

\begin{tabular}{lccccccc}
\hline \hline Element & $Z$ & $b_{\mathrm{M}}$ & $c_{\mathrm{M}}$ & $\begin{array}{c}E_{\min } \\
(\mathrm{keV})\end{array}$ & $\begin{array}{l}E_{\max } \\
(\mathrm{keV})\end{array}$ & $U_{\min }$ & $U_{\max }$ \\
\hline $\mathrm{Au}$ & 79 & $0.795 \pm 0.001$ & $1.238 \pm 0.002$ & 5.50 & 83.2 & 2.1 & 32.2 \\
$\mathrm{~Pb}$ & 82 & $0.791 \pm 0.001$ & $1.263 \pm 0.002$ & 6.12 & 84.5 & 2.1 & 29.1 \\
$\mathrm{Bi}$ & 83 & $0.788 \pm 0.001$ & $1.274 \pm 0.002$ & 6.41 & 87.1 & 2.1 & 28.9 \\
\hline \hline
\end{tabular}

each region, we made linear fits and obtained values of the Bethe parameters, $b_{i}$ and $c_{i}$. Values of $b_{i}$ for the high-energy regions were determined from the asymptotic high-energy slopes of the Fano plots after which $c_{i}$ values could be calculated. The resulting straight lines were extrapolated to lower energies at which the deviations between the straight lines and each plot became 5\%. The linear fits for the low-energy regions were made over energy ranges for which the deviations between the fit and each plot were also less than 5\%. Our values of $b_{i}$ and $c_{i}$ for each element and shell are presented in Tables I-VI together with the energy ranges for which they can be used. For the high-energy fits, the minimum overvoltage ranged from about 40 for K-shell ionization of $\mathrm{C}, \mathrm{N}, \mathrm{O}$, and $\mathrm{Ne}$ to around 430 for $\mathrm{Pb}$ and $\mathrm{Bi}$ while the minimum overvoltage varied from about 60 for L-shell ionization of $\mathrm{Ag}$ and $\mathrm{Sn}$ to around 160 for $\mathrm{U}$; for M-shell ionization of $\mathrm{Au}, \mathrm{Pb}$, and $\mathrm{Bi}$, the minimum overvoltage was around 38. For the low-energy fits, the overvoltage ranged from between around 2 and 20 for K-shell ionization of $\mathrm{C}$, $\mathrm{N}, \mathrm{O}$, and $\mathrm{Ne}$ to between 1.7 and about 8 for $\mathrm{Au}, \mathrm{Pb}$, and $\mathrm{Bi}$, and the corresponding overvoltage ranged from between 1.6 and about 18 for L-shell ionization of $\mathrm{Ag}$ and $\mathrm{Sn}$ to between 1.9 and about 12 for $\mathrm{Pb}, \mathrm{Bi}$, and $\mathrm{U}$; for $\mathrm{M}$-shell ionization, the overvoltage ranged between about 2 and about 30 for $\mathrm{Au}, \mathrm{Pb}$, and $\mathrm{Bi}$.

We found systematic variations of $b_{i}$ and $c_{i}$ with $Z$. Values of $b_{\mathrm{K}}$ for the high-energy regions of the Fano plots decreased monotonically from about 0.52 for $\mathrm{C}, \mathrm{N}, \mathrm{O}$, and 

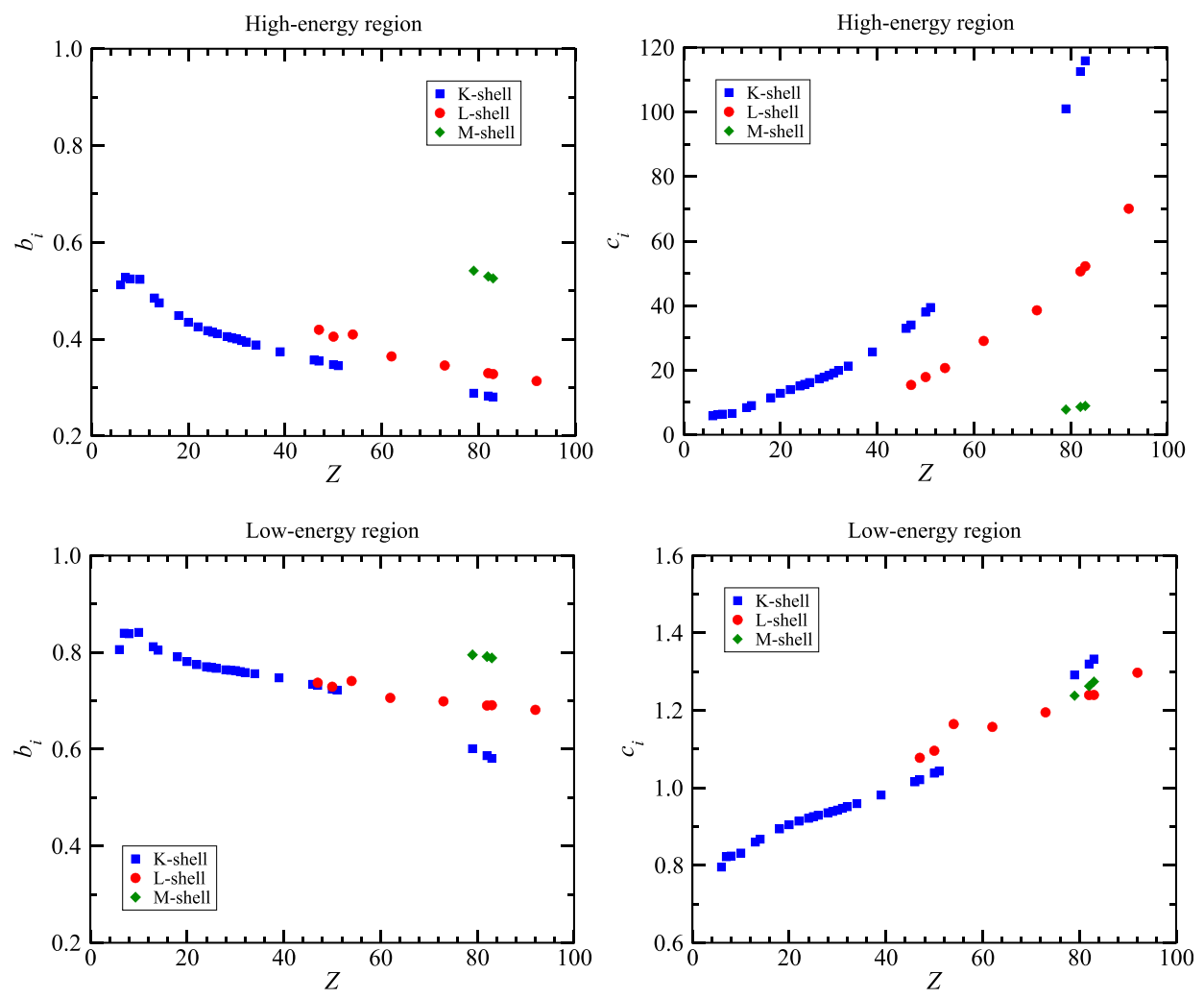

FIG. 17. Plots of the Bethe parameters $b_{i}$ and $\mathrm{c}_{i}(i=\mathrm{K}, \mathrm{L}$, or $\mathrm{M})$ as a function of $Z$ from fits with Eq. (8) in the high-and low-energy regions of the Fano plots in Figs. 1-16 for K-shell ionization (blue squares), L-shell ionization (red circles), and M-shell ionization (green diamonds). The left panels show plots of $b_{i}$ while the right panels show plots of $c_{i}$. The top panels show the Bethe parameters from the fits in the high-energy regions of the Fano plots (Figs. 1-5 for Kshell ionization, Figs. 11 and 12 for L-shell ionization, and Fig. 15 for M-shell ionization, as listed in Tables I, III, and V). The bottom panels show the Bethe parameters from the fits in the low-energy regions of the Fano plots (Figs. 6-10 for K-shell ionization, Figs. 13 and 14 for L-shell ionization, and Fig. 16 for M-shell ionization, as listed in Tables II, IV, and VI). Error bars, corresponding to one-standard-deviation uncertainties of the Bethe parameters obtained from the fits with the low-energy Fano plots, are smaller than the size of the symbols. Values of $b_{\mathrm{L} 3}$ and $c_{\mathrm{L} 3}$ for Xe are also included in each panel with values of $b_{\mathrm{L}}$ and $c_{\mathrm{L}}$, respectively.

$\mathrm{Ne}$ to about 0.28 for $\mathrm{Au}, \mathrm{Pb}$, and $\mathrm{Bi}$ while values of $b_{\mathrm{L}}$ decreased from about 0.41 for $\mathrm{Ag}$ and $\mathrm{Sn}$ to about 0.32 for $\mathrm{Pb}, \mathrm{Bi}$, and $\mathrm{U}$, and $b_{\mathrm{M}}$ was about 0.53 for $\mathrm{Au}, \mathrm{Pb}$, and $\mathrm{Bi}$. There were much larger variations in $c_{\mathrm{i}}$ with $Z$ for the highenergy regions, with $c_{\mathrm{K}}$ increasing from about 5.9 for $\mathrm{C}$ to 116 for $\mathrm{Bi}$, and $c_{\mathrm{L}}$ increasing from about 15 for $\mathrm{Ag}$ to about 70 for U. For the low-energy regions of the Fano plots, $b_{\mathrm{K}}$ decreased from about 0.84 for $\mathrm{N}, \mathrm{O}$, and $\mathrm{Ne}$ to 0.581 for $\mathrm{Bi}$, the values of $b_{\mathrm{L}}$ decreased from about 0.74 for $\mathrm{Ag}$ to about 0.68 for $\mathrm{U}$, and $b_{\mathrm{M}}$ was about 0.79 for $\mathrm{Au}, \mathrm{Pb}$, and $\mathrm{Bi}$. There are much smaller variations of $c_{i}$ with $Z$ for the low-energy fits than for the high-energy fits, with $c_{\mathrm{K}}$ varying between 0.796 for $\mathrm{C}$ to about 1.3 for $\mathrm{Au}, \mathrm{Pb}$, and $\mathrm{Bi}$, with $c_{\mathrm{L}}$ ranging between 1.078 for $\mathrm{Ag}$ to 1.297 for $\mathrm{U}$, and with $c_{\mathrm{M}}$ about 1.26 for $\mathrm{Au}, \mathrm{Pb}$, and $\mathrm{Bi}$.

Our values of $b_{i}$ and $c_{i}$ for the elements in Tables I-VI can be used to determine cross sections from the Bethe equation for ionization of $\mathrm{K}, \mathrm{L}$, and $\mathrm{M}$ shells by electron impact for the designated energy or overvoltage ranges. Similar evaluations can be made for other elements with values of $b_{i}$ and $c_{i}$ determined by interpolation. For many applications, however, it may be more convenient to determine these cross sections, for any element and for any energy from the ionization threshold to $100 \mathrm{GeV}$, from the empirical equations and parameters published by Bote et al. ${ }^{8}$

\section{ACKNOWLEDGMENTS}

Financial support from the Spanish Ministerio de Economía y Competitividad and the European Regional Development Fund (Project No. FPA2013-44549-P) and from the Generalitat de Catalunya (Grant No. 2014 SGR 846) are gratefully acknowledged.

${ }^{1}$ H. Bethe, Ann. Phys. 397, 325 (1930).

${ }^{2}$ M. Inokuti, Rev. Mod. Phys. 43, 297 (1971).

${ }^{3}$ U. Fano, Phys. Rev. 95, 1198 (1954).

${ }^{4}$ C. J. Powell, Rev. Mod. Phys. 48, 33 (1976).

${ }^{5}$ C. J. Powell, in Electron Impact Ionization, edited by T. D. Märk and G. H. Dunn (Springer-Verlag, Vienna, 1985), Chap. 6, pp. 198-231.

${ }^{6}$ C. J. Powell, in Microbeam Analysis-1990, edited by J. R. Michael and P. Ingram (San Francisco Press, San Francisco, 1990), p. 13-20.

${ }^{7}$ D. Bote and F. Salvat, Phys. Rev. A 77, 042701 (2008).

${ }^{8}$ D. Bote, F. Salvat, A. Jablonski, and C. J. Powell, At. Data Nucl. Data Tables 95, 871 (2009); erratum: 97, 186 (2011).

${ }^{9}$ X. Llovet, C. J. Powell, F. Salvat, and A. Jablonski, J. Phys. Chem. Ref. Data 43, 013102 (2014).

${ }^{10}$ S. Tanuma, C. J. Powell, and D. R. Penn, Surf. Interface Anal. 43, 689 (2011).

${ }^{11}$ F. J. de Heer and M. Inokuti, in Electron Impact Ionization, edited by T. D. Märk and G. H. Dunn (Springer-Verlag, Vienna, 1985), Chap. 7, pp. 232-276.

${ }^{12}$ G. P. Williams, in CRC Handbook of Chemistry and Physics, 91st ed., edited by W. M. Haynes and D. R. Lide (CRC Press, Boca Raton, 2011), Sect. 10, pp. 221-226. 